This item was submitted to Loughborough's Research Repository by the author.

Items in Figshare are protected by copyright, with all rights reserved, unless otherwise indicated.

\title{
"I'm a bit concerned" - early actions and psychological constructions in a child protection helpline
}

PLEASE CITE THE PUBLISHED VERSION

http://dx.doi.org/10.1207/S15327973RLSI3603_01

\section{PUBLISHER}

Taylor \& Francis (Routledge) @ Lawrence Erlbaum Associates, Inc.

\section{VERSION}

AM (Accepted Manuscript)

LICENCE

CC BY-NC-ND 4.0

\section{REPOSITORY RECORD}

Potter, Jonathan, and Alexa Hepburn. 2019. "i'm a Bit Concerned" - Early Actions and Psychological Constructions in a Child Protection Helpline". figshare. https://hdl.handle.net/2134/9493. 
This item was submitted to Loughborough's Institutional Repository (https://dspace.lboro.ac.uk/) by the author and is made available under the following Creative Commons Licence conditions.

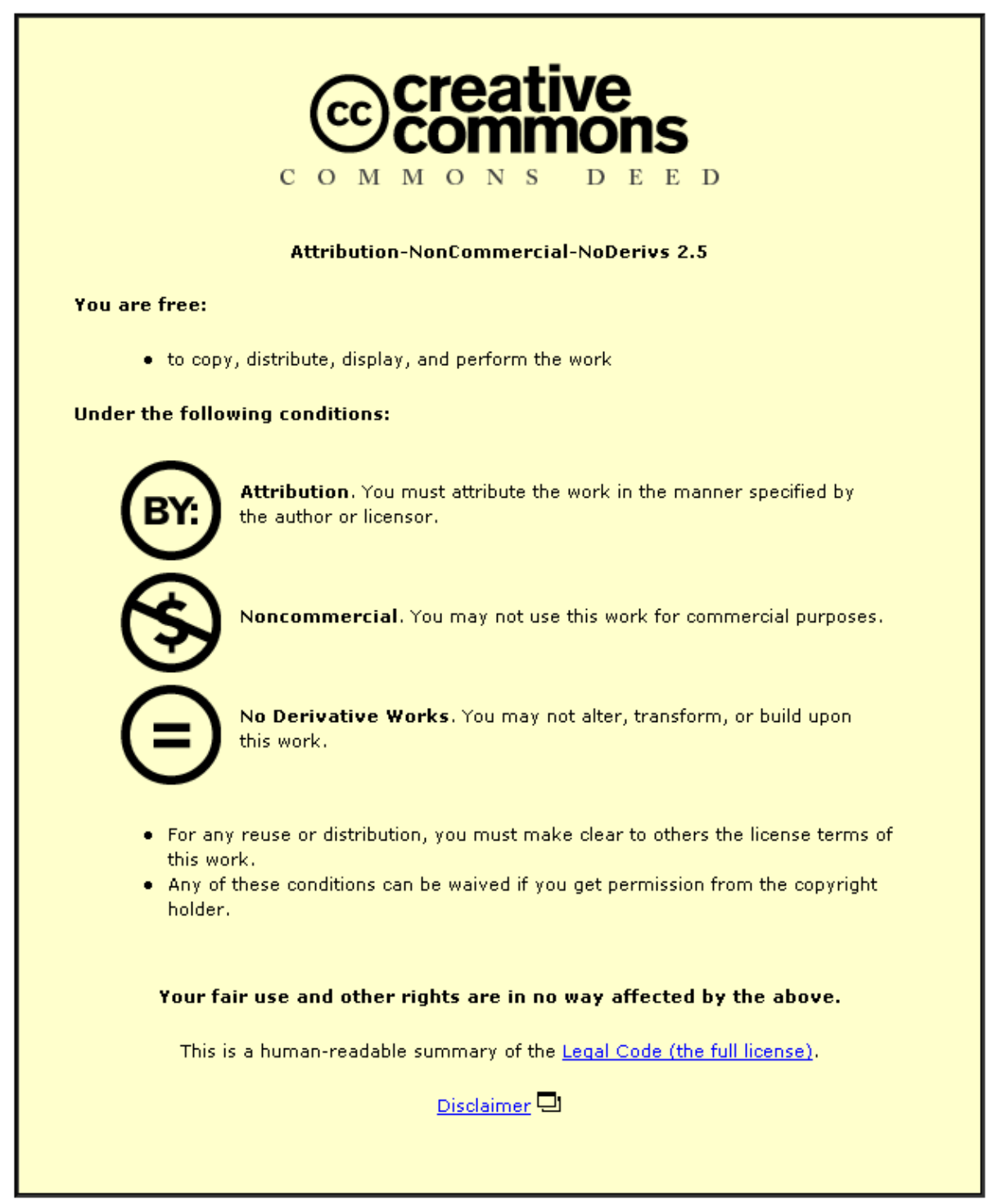

For the full text of this licence, please go to: http://creativecommons.org/licenses/by-nc-nd/2.5/ 


\section{'I'M A BIT CONCERNED' - EARLY ACTIONS AND PSYCHOLOGICAL CONSTRUCTIONS IN A CHILD PROTECTION HELPLINE}

\section{Jonathan Potter \& AleXa HePburn}

Discourse and Rhetoric Group

Department of Social Sciences

Loughborough University

Loughborough

Leicestershire, LE11 3TU
Email: J.A.Potter@lboro.ac.uk

Email: A.Hepburn@lboro.ac.uk

Tel: 01509223384

Tel: 01509223876

Fax: 01509223944

To appear in: Research in Language and Social Interaction, in press.

We would like to thank Wayne Beach, Derek Edwards, John Heritage, Doug Maynard, Anssi Peräkylä, and audience members at the NCA in Atlanta, November 2001, ICCA in Copenhagen, May 2002 and Texts, Interaction \& Ethnography in Tampere, June 2002, for making helpful comments on earlier versions of this paper. This paper has benefited greatly from the diligence and thought of the ROLSI referees, and editor Don Zimmerman. We would like to also thank the staff at the UK National Society for the Protection of Cruelty to Children their time and effort. This research was partially supported by a research fellowship from the Leverhulme Trust awarded to the second author. 
'I'M A BIT CONCERNED' - EARLY ACTIONS AND PSYCHOLOGICAL CONSTRUCTIONS IN A CHILD PROTECTION HELPLINE

\begin{abstract}
This paper analyses early actions in 50 calls reporting cases of abuse to a national child protection helpline in the UK (the National Society for the Prevention of Cruelty to Children helpline). It focuses in particular on the early turns in the caller's 'reason for call', and in particular a class of constructions in which the caller describes him or herself as being 'concerned about x' (or similar). Analysis of the corpus of calls suggests concern constructions are canonical early elements of the reason-for-call sequence. Concern constructions (a) are oriented to as a pre-move in the caller's reason for call; (b) project the unpacking of concerns in a way oriented to the NSPCC's institutional role; (c) attend to epistemological asymmetries between caller and call taker and remove the requirement for disaffiliative next actions such as asking for the basis of claims; (d) provide a way for the Child Protection Officer to take abuse claims seriously while not presupposing their truth; (e) display an appropriate caller stance. These observations are supported by an analysis of deviant cases. The broader implications of this study for the relation between psychology, interaction and institutions are discussed.
\end{abstract}


This paper has two major themes. First, and most importantly, it aims to explicate a practice that takes place early on in calls to a child protection helpline in the UK. In particular, it considers the role of 'psychological' constructions such as 'concern' (being concerned, having concerns) for managing a range of issues to do with asymmetry, epistemological authority, and the speaker's stance toward what they are reporting. The analysis will draw on the tradition of work pioneered in conversation analysis for the study of institutional interaction (Drew \& Heritage, 1992; Heritage, 1997) and builds on a specific strand of work on calls to emergency services (Zimmerman, 1992). It identifies a particular class of constructions that manage a number of early call tasks in a coordinated and collaborative manner.

The second theme is focused on the broader question of how psychology figures as an object in, and a resource for, interaction. Concern constructions are particularly interesting for their potential psychological implications. The analysis will draw on recent work in the study of psychology and interaction (Edwards, 1997; Potter, 1998) and will address questions of the institutional specificity of psychological discourse. The general aim will be to show how psychological constructions can be seen as a means for performing practical tasks, and how those tasks are embedded in particular institutional organizations.

\section{HELPLINES AND INSTITUTIONAL PHONE CALLS}

There has been a huge growth in the last decade in the use of telephone helplines in the UK to offer distributed support for social issues such as health, parenting, bullying, mental disorder, and substance abuse (Telephone Helplines Association, 1999). This provides an important topic for applied study, as well as an interesting arena for addressing theoretical issues in applied conversation analysis (Heritage, 2002) and discursive psychology (Edwards \& Potter, 2001). 
In some of his earliest work, of course, Sacks (1992) worked on calls to a suicide prevention line. However, there is only a small amount of recent published work on telephone helpline interaction. Baker and colleagues (Baker, et al., 2001; Danby, et al, in press) studied early actions in calls to a computer support line. They identified a set of regular features in the way calls develop. We will explicate some of the differences between the operation of the computer support helpline and that of the NSPCC below.

Although little work has yet been published on helplines, research on both mundane phone calls (particularly Schegloff, 1986) and calls for emergency assistance provides an important body of comparative work. Work on calls to emergency services (Whalen \& Zimmerman, 1987, 1990; Whalen, et al., 1988) has important parallels with the current materials. Both can involve reports of events that may be traumatic or life threatening, and involve information collection for the use of another party. We will draw out more specific connections with this work in the course of the analysis.

The broader literature on advice and counselling is relevant in a number of ways. Peräkylä's (1995) work on AIDS counselling and Edwards' (1995) on relationship counselling both identify a range of subtle practices of description and advice giving. There is some connection with the small literature on telephone counselling (e.g. Hopper, et al., 1995).

The literature on professional client relationships, particularly doctor patient relationships can provide another useful parallel (Heritage \& Sefi, 1992; Silverman, 1987). In particular, it highlights the importance of the way patients present as appropriately needing the services of the doctor and the way the doctor's epistemic authority is collaboratively managed (e.g. Frankel, 2001; Heritage \& Lindström, 1998). 


\section{COGNITION, INTERACTION AND INSTITUIONS}

The relation of psychology (mind, cognitive processes, and so on) to interaction is a complex and contentious one. On the one hand, some strands of work have the objective of joining up the research findings of mainstream cognitive psychology and social cognition with interaction research (Clark, 1992; Graesser, et al., 1997; van Dijk, 1997). On the other, some researchers have argued that the idea that behaviour is generated by inner states and entities is an incoherent one (Coulter, 1990, in press).

There are various alternatives to these 'bolt-on' and 'eliminative' positions. Some conversational analytic research has considered how mental states and processes (although not necessarily those of established paradigms of social cognition and cognitive science) may figure in interaction (Drew, 1995, in press; Heritage, in press; Pomerantz, 1990/91; Schegloff, 1991). Some ethnomethodological work has focused on the practical role of cognitivist notions such as memory or plans (Lynch \& Bogen, 1996, in press). For example, Suchman (1987) suggests that the notion of a plan is better thought of as a post-hoc way of providing coherence and accountability to situated actions rather than a mentally represented template acting on behaviour.

The discursive psychological approach to cognition taken here brackets off ontological judgements about the existence of cognitive phenomena such as mental states and processes, and instead approaches cognition as a members' concern (Edwards, 1997; Edwards \& Potter, 1992, in press; Potter, 1998). ${ }^{1}$ That is, it considers (a) practices involving psychological terms; (b) practices involving psychological themes and orientations; (c) critique and respecification involving a detailed consideration of the role of discourse in cognitive research. The interest here will be in exploring the link between these issues and institutional interaction (cf. Edwards \& Potter, 2001):

1. Are institutions characterised by specific 'psychological' business? 
2. Does this business partly constitute the institutional form?

3. Does this business draw on, but modify mundane psychological business?

\section{ANALYTIC MATERIALS AND PROCEDURES}

The NSPCC (National Society for the Prevention of Cruelty to Children) is Britain's principal child protection charity and is unique in possessing statutory powers to safeguard children. Much of their direct contact is through a 24 hour National Child Protection Helpline that receives 250,000 calls per year. The NSPCC is legally mandated to pass on reports of abuse to social services and/or police where the information is sufficient and merits action, whether the caller wishes this or not. The helpline also provides free counselling, information and advice to anyone concerned about a child at risk of ill treatment or abuse, or to children themselves who may be at risk. It is staffed by trained social workers with at least 3 years field experience of working in child protection.

The NSPCC has a high profile in the UK where it has been active for over 100 years. It advertises on television and in media outlets, and uses posters and stickers to generate funds, campaign on issues (currently: 'Child abuse deaths must stop. FULL STOP'), and advise people on how they can offer and receive help. A current poster is headed 'Don't keep it to yourself'. Below this is 'NSPCC child protection helpline' with the number and 'Full Stop' logo; then there is text below which reads:

If you:

- are a child or young person and you need help,

- know or believe that a child or young person needs to be kept safe,

- are an adult, parent, carer or relative and need advice or help, please call the NSPCC Child Protection Helpline on..

Examples of posters and the general style of the NSPCC's approach to support can be seen on their website at www.NSPCC.org.uk. 
The research is based at the NSPCC's London call centre where up to 18 call takers may be on duty at any one time in shifts of between 6 and 10 hours. They make notes on information given during calls. These are typically typed up onto a PC after the call; during a call the PC may be used for accessing information, such as the phone number of a Social Services department. Calls are highly varied. They come from adults, young people, grandparents, parents and neighbours, from people of different social class and ethnic backgrounds from all over Britain. They can be asking for advice, reporting abuse, requiring counselling. Some issues may be relatively trivial; some may be literally life or death. They can last for a few minutes or stretch to over an hour. Some callers will call back for further advice or with further information. Where serious abuse is suspected the call taker will follow the call directly with a referral to the relevant police force, or, more often, Social Services.

The call takers have the job title Child Protection Officer (henceforth CPO), and we follow this in our transcription. The CPOs taking part in this study 'hot desked' a workstation that routed their calls via a minidisk recorder. All participants to the study consented to their calls being recorded for research and training purposes. All identifying details have been anonymized in our presentation of transcript. The calls were transcribed initially by a transcription service, and then developed toward standard Jeffersonian form by the second author (see, for example, Hutchby \& Wooffitt, 1998). Analysis worked with the combination of digitised recording and transcript.

The general aim of this programme of research is to make explicit the skilled ways in which calls are dealt with and to consider the nature and consequence of troubles that arise in the calls. It will produce information and audio video training materials to help the NSPCC and similar organizations in their training and quality assurance, as well as consider theoretical and analytic issues that arise in dealing with these materials. 
For the analysis reported here we have focused on a corpus of 50 call openings that reported abuse to a $3^{\text {rd }}$ party. We produced the corpus by eliminating those calls that were from victims of abuse themselves, as well as other less typical actions such as attempts to donate and calls thanking CPOs for their work. The 50 call openings were taken by 12 different CPOs and vary in length from 5 to 50 minutes, averaging around 16 minutes. Our selection from a gradually increasing corpus of calls was guided by the pragmatics of research - it is a large enough corpus to include different CPOs and a range of different types of caller, and thus large enough to make plausible generalizations from; at the same time, it was small enough for the task of transcription and analysis to be manageable. ${ }^{2}$

\section{OPENING THE CALL}

We will start our analysis by considering some of the ways in which early actions in the NSPCC helpline calls differ from other kinds of call. Whalen \& Zimmerman (1987) have noted that calls to emergency numbers exhibit two contrasts to casual telephone conversations. First, they show specialization and, in particular, the openings are identification-oriented ('Mid-City Emergency') rather than recognition-oriented ('Hello'). Second, they show a reduction of standard features of opening sequences such as 'howareyous'. So while everyday phone calls may take around 10 turns to get to first topic (Schegloff, 1986) emergency calls may get to the first topic, in this case the 'reason for call' (RFC) as early as turn two.

\begin{tabular}{|l|ll|l|}
\hline 0 & Ring & summons \\
\hline 1 & CT: & Mid-City Emergency & Identification-oriented answer \\
\hline 2 & C: $\quad$.hh Um: yeah (.) & acknowledgement \\
& Somebody jus' vandalized my=ca: $r$, & first topic (reason for call - RFC) \\
\hline
\end{tabular}


Zimmerman (1992) has described a range of organizational features of emergency calls. Most relevantly to our current concern he describes four common constructions of RFCs that immediately follow the identification-oriented answer (from Zimmerman, 1992, pp. 435-441).

1. They can be in the form of requests that intimate policeable or medical trouble without specifying the nature of the problem:

C: I need the paramedics please

2. They can be in the form of reports that name trouble that may be appropriate for the attention of emergency services:

C: I want to report a real bad accident

3. They can be in the form of descriptions that inform the dispatcher about a problem with some minimal context:

C: In the YWCA parking lot there uh bunchuh teenagers right
vandalizing my ca:r,

4. They can be in the form of narratives - extended, chronologically organized descriptions that build towards a characterization of the potential trouble. ${ }^{3}$

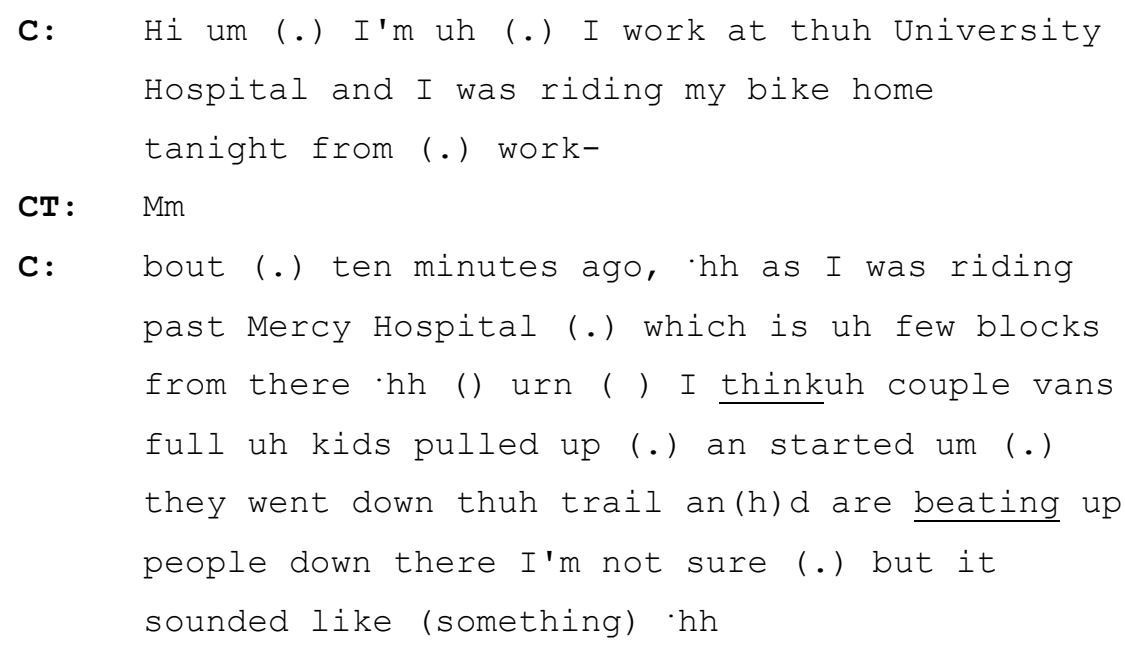

How do calls to the NSPCC compare with these emergency calls? Both emergency and NSPCC calls are characterised by the reduced opening and the identification-oriented answer. This is followed by the reason for call, which is, with a 
few interesting exceptions, most similar in character to Zimmerman's narrative RFCs.

Take the following example.

1a. LB neighbour concern

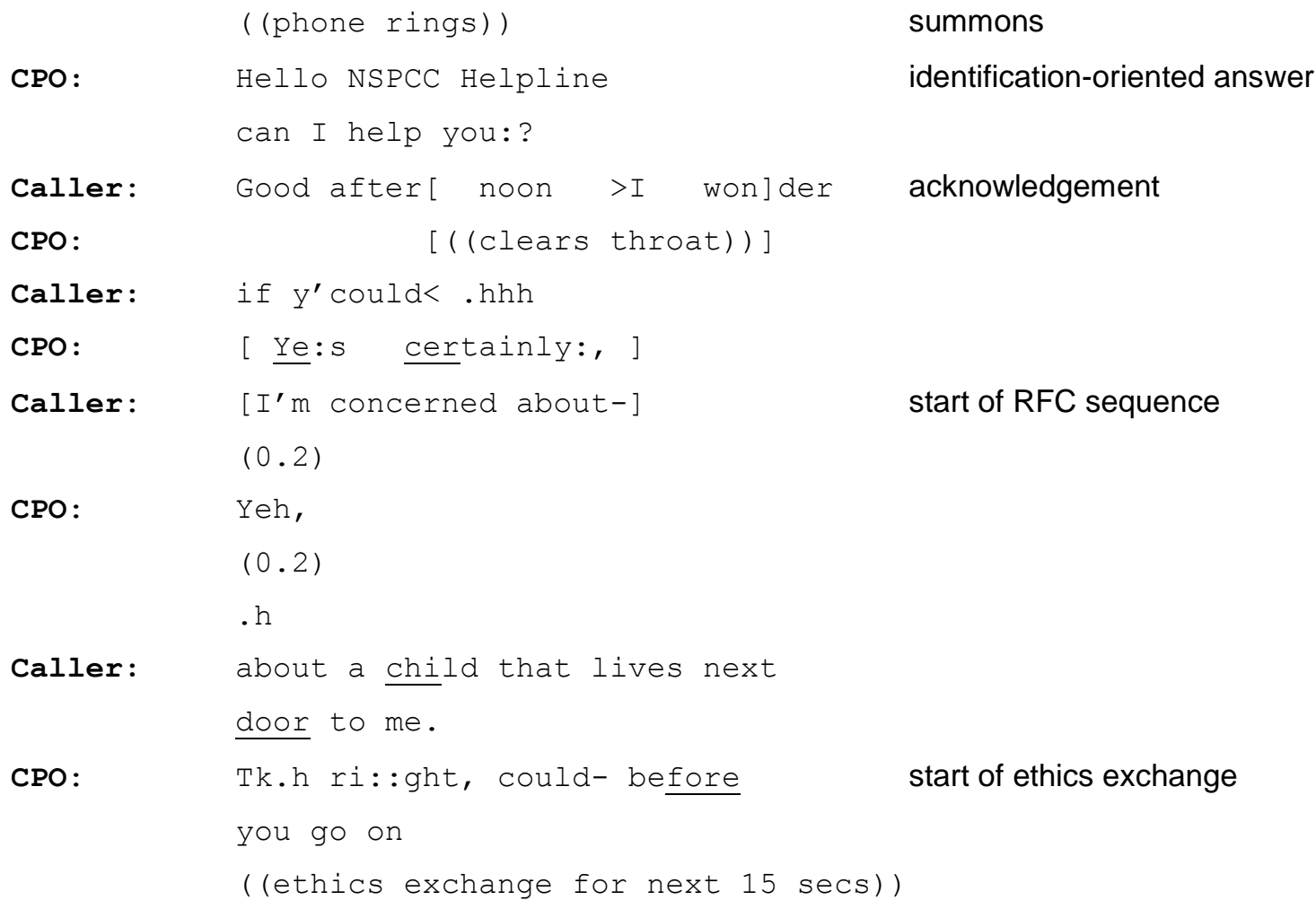

CPO: Tk.h ri::ght, could-before start of ethics exchange

summons

identification-oriented answer

acknowledgement

start of RFC sequence

Note the telephone summons in line 1 and the identification-oriented answer in line 2

The caller offers an acknowledgement at this point. Then in line 8 (after a brief insertion) the RFC sequence starts. It is the nature and role of the early parts of the RFC sequence that is the main topic of this paper.

One of the things we noticed when first researching this topic was the prevalence of RFC initiations like the one above. ${ }^{4}$ That is, they often started with the caller describing him or herself as 'concerned'. Indeed, in our sample of 50 calls 30 of them start with either caller or $\mathrm{CPO}$ using a concern construction (or equivalent). ${ }^{5}$

The concern construction is in lines 8-14.

'I'm concerned about a child that lives next door'

Schematically we can describe the canonical concern construction as: 
where $\mathrm{X}$ is an object (usually a person) or an action (usually violence or neglect). We will consider the way the concern construction works in the RFC to manage a range of institutional and practical issues including the authority of the report, the stance of the caller to what is reported, and the neutrality of the CPO. We will start with some canonical examples, and then explore some potential deviant cases. In due course, we will suggest that concern constructions are best seen as a collection of similar constructions that are used to do similar work, not all of which use the lexical item 'concerned'. However, we will keep the name 'concern construction' as constructions using this lexical item are the clearest and most common examples.

\section{CANONICAL CONCERNS FORMATS}

\section{1: Caller Opens with Concern Construction}

Let us return to the call in 1a. The caller opens the RFC with a concern construction. The $\mathrm{CPO}$ intervenes at the first transition relevant place to initiate the ethics exchange. For reasons of space we have not included the sometimes lengthy ethics exchanges here. When the ethics exchange is complete the caller restarts with a reiteration of the concern construction.

1b. LB neighbour concern

( (phone rings))

CPO: Hello NSPCC Helpline can I help you:?

Caller: Good after[ noon >I won]der if $\mathrm{Y}^{\prime}$

CPO: [((clears throat)) ]

Caller: $\quad$ could $<$. hhh

CPO: [ $\quad$ Ye:s certainly:, ]

Caller: [I'm concerned about-]

$(0.2)$

CPO: Yeh,

$10 \quad(0.2)$

$11 . \mathrm{h}$

12 Caller: about a child that lives next

13 door to me. 


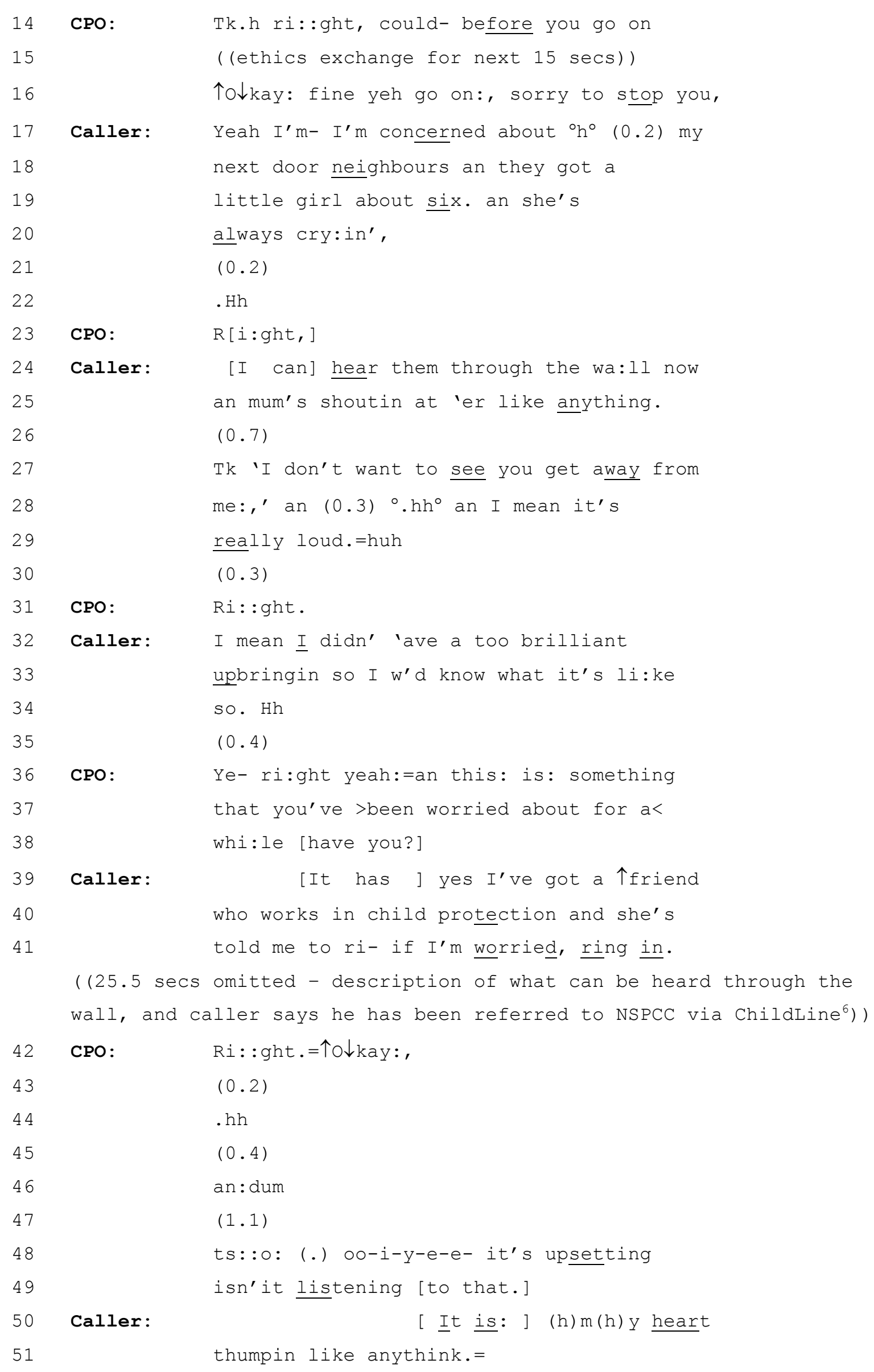




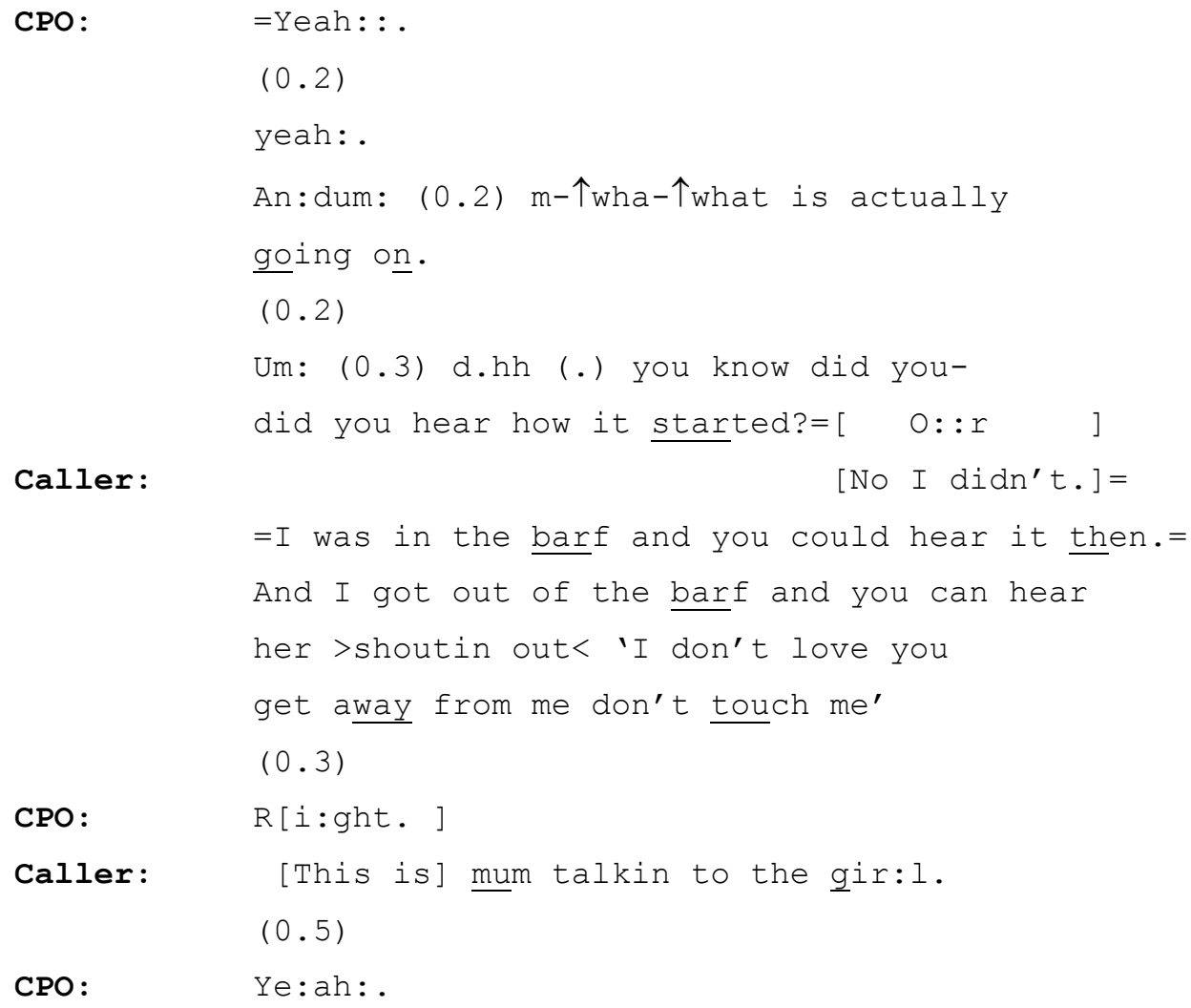

Let us start by making a number of observations about this call that are relevant to the activities done and the role of the concern construction.

First, note that the CPO at 14 does not treat the caller as having completed an action after the concern construction. His 'before you go on' treats the caller as having more to say and being about to go on to say it. Likewise, his 'sorry to stop you' on line 16 treats the caller as having been stopped from doing something.

Second, note the CPO's 'right' on 14. It is neither assessing the prior turn, nor moving on to new business. It seems to be an acknowledgement token (cf. Heritage \& Sorjonen, 1994; Schegloff, 1982). The CPO, therefore, appears to treat the concern construction as the start of something, but not its end. Likewise with the CPO's 'right' on line 23.

Third, note that after the intrusion of the ethics exchange the caller resumes with a reiteration of the concern construction. ${ }^{7}$ Schegloff (1987) has suggested that turn beginnings are structurally important places and that they may be recycled when 
impaired (e.g. by overlaps). The recycling in this case suggests that the concern construction has a particular social-interactional function for the caller (cf. extracts 3 and 4 below). Specifically, it allows the caller to start his delivery with the concern construction rather than further into the narrative.

Fourth, note that, after the acknowledgement token on 23, the caller continues with a range of relevant descriptions that might suggest violence and abuse, and attend to the caller's knowledge and possibly their motive for calling.

Fifth, note that after further acknowledging what the caller has said, the CPO asks a first question on 36-38. The design of this question is particularly interesting. It does not ask (directly) about the events that the caller is describing, but asks about the caller's 'worries' (this occasions an account for making the call and an extended description of what can be heard). It is not until lines 55 to 59 that the CPO asks directly about events. And even this asking is complex and open-ended, opening the way for a range of different responses. ${ }^{8}$

These features suggest that concern constructions are treated here by caller and CPO as projecting a possibly extended narrative relating to possible violence to a child. Concern constructions are hearably incomplete. The caller and CPO treat the concern construction as projecting institutionally relevant issues that are 'to come' in an extended telling. It also presents the stance of the caller to the narrative.

One further complexity is worth highlighting. The concern construction projects collaborative unpacking in the sense that they do not start with a definitive claim about the status of the putative abuse, but a concern, which can be made more definitive in discussion with the CPO. The initial stance is one of uncertainty about the object of concern and its status as NSPCC actionable abuse. Whatever else this does, it projects a call appropriate to the NSPCC (rather than the police, say). We can contrast the 
canonical concern construction preface to the RFC with Zimmerman's (1992) examples quoted above (e.g. 'somebody jus' vandalized my car'). If the abuse is too clear, or immediate, or severe it might be that calling the NSPCC rather than police or social services would be a negligent action. This is a regular orientation in the calls where caller or CPO refers to the possibility of calling the police. For example, near the end of the above call we get:

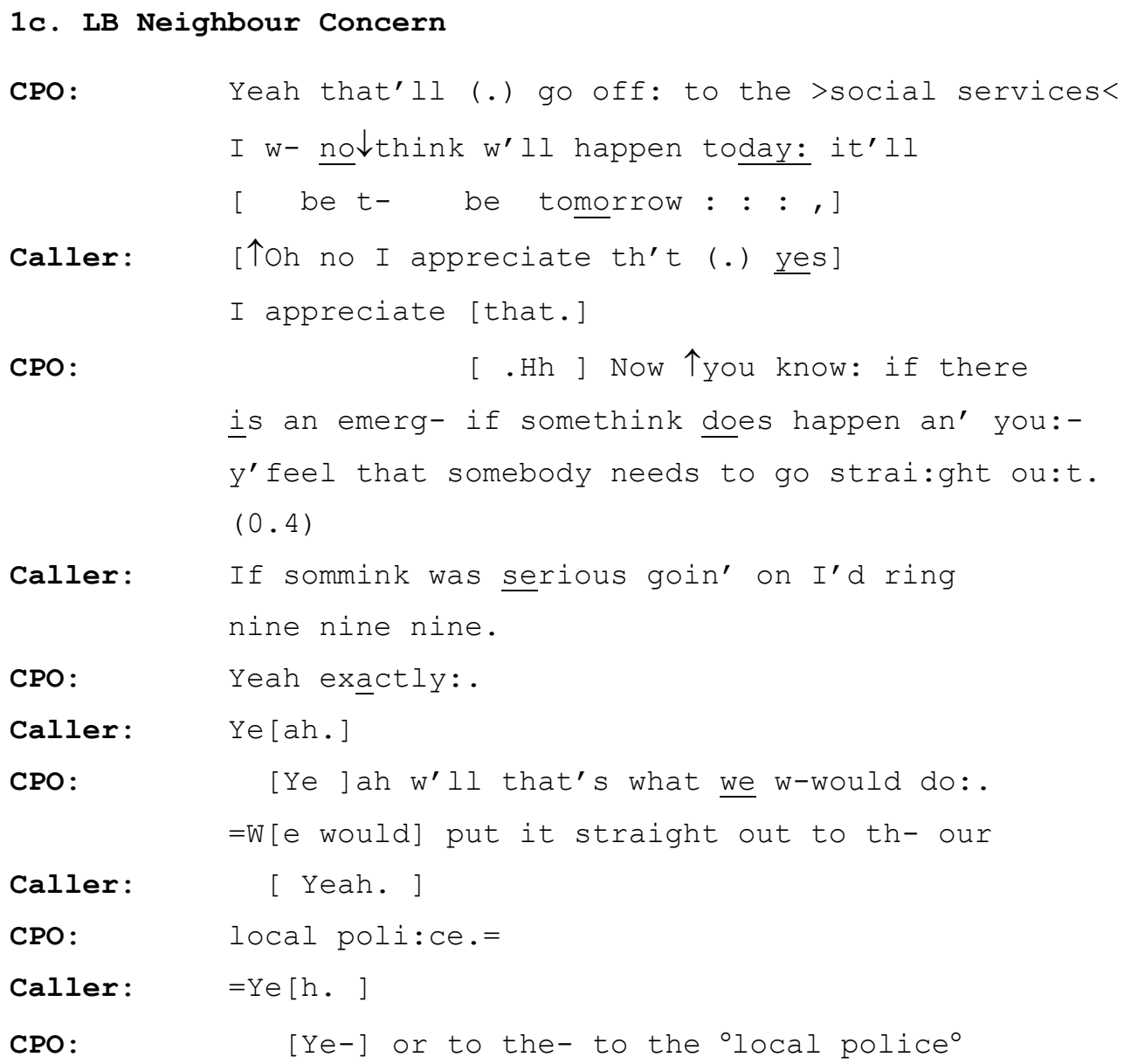

In this case the caller takes 'something serious' as the contrast case to this, where the police should be called. Yet if we consider various aspects of the start of the RFC in Extract $1 \mathrm{~b}$ we can see various descriptive features that work toward building seriousness of the report. The child is 'always crying', the mum is 'shouting at 'er like anything' (with what is shouted actively voiced by the caller - Wooffitt, 1992), it is 'really loud'. There is a careful attention to what is the appropriate basis to call the NSPCC versus the 
police. The concern construction projects something serious enough for the NSPCC, but not (yet) definitive or serious enough for the police. It is notable that concern constructions do not figure in the collection of RFCs reported in Zimmerman (1992).

Here is a second example, starting post ethics exchange.

\section{BN Father and school}

Thank you very much indeed. (.) how can I help.

Right (.) .hh er::m: (0.6) I'm concerned

because:: : er: my $\uparrow$ son goes to a school,

$(0.6)$

Tch

$(0.1)$

$\mathrm{U}:: \mathrm{m}$ (.) and I'm concerned about the

type of punishm(h)ent (0.2) .hh (0.3)

that (0.6) they: are: : (.) u::m: ${ }^{\circ} \downarrow::^{\circ}$

administering.

$(0.5)$

Er: as a form of discipline.

$(0.3)$

$\circ . h h\left[h h^{\circ}\right]$

CPO :

[How] old's your son?

Caller: Er ' $e$ 's nine.

$(0.7)$

CPO : $\quad \mathrm{Mm} .=$

Caller: =Kay, .HHHh er::m: (.) can $\uparrow I j^{\prime} s$ tell

you what it is $\downarrow_{\text {first }}$ of $[a: 11$.

CPO :

[Yes of] cou:rse.=

Caller:

$=\mathrm{Er}:: \mathrm{m} \quad(.) \mathrm{a}:$ ndhhs $:(0.2) \mathrm{b}^{\prime} \mathrm{C}^{\prime} \mathrm{s} I-$

(0.2) Hhh (.) I d- $\uparrow I$ don't know if it's me

overreacting.

(.)

.Hh okay.

$(0.2)$

个All it was the children- there was five

children all playfi:ghting:

$(0.3)$

er: : : m:

$(0.2)$ 


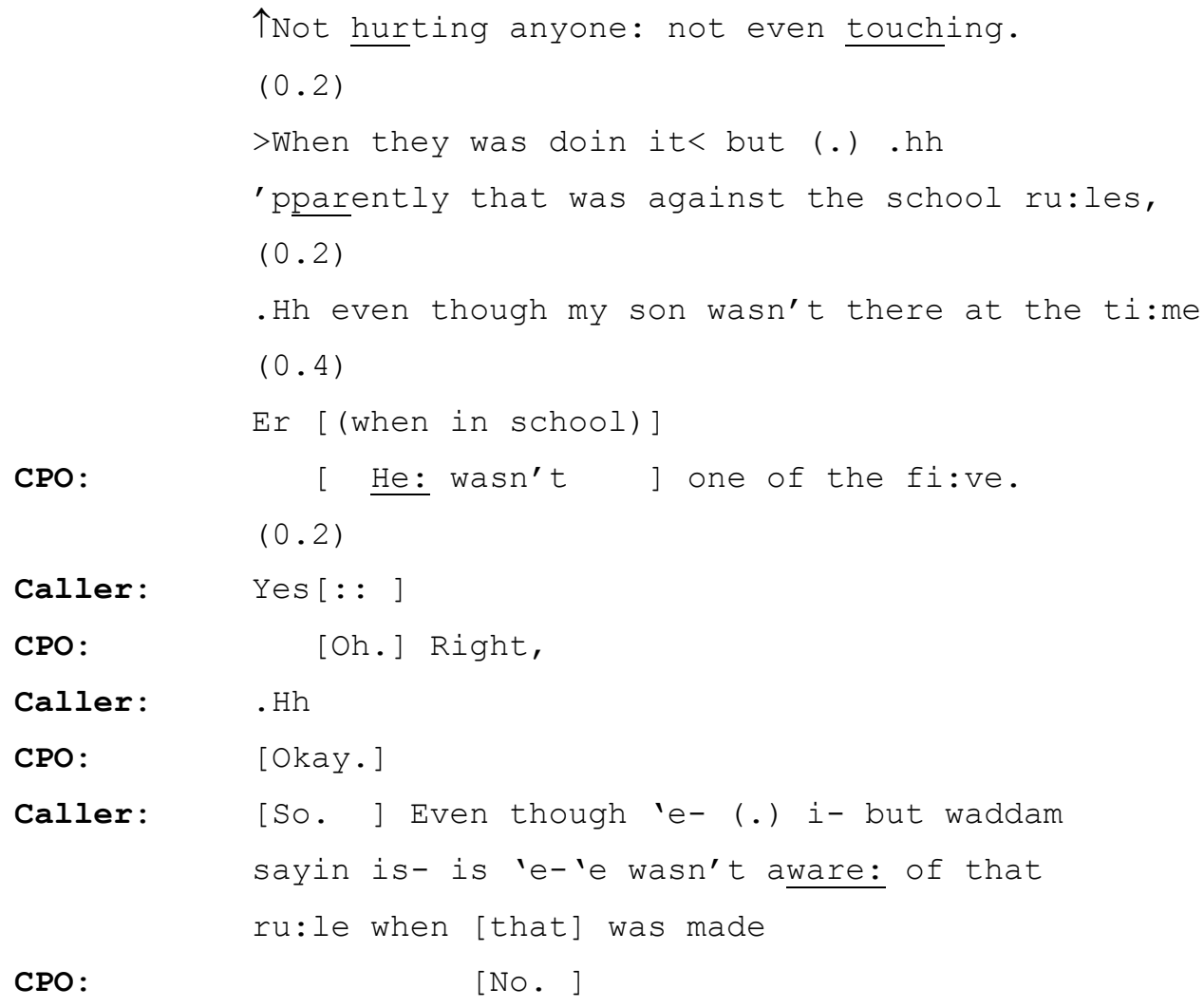

In this case the concern construction in lines 2 to 12 is focused on an action. It can be put schematically as 'I am concerned about $\mathrm{X}$ ' where $\mathrm{X}$ is punishment that the school has administered to the caller's son. Consider how the sequence unfolds from line 2. Line 11 would be an opportunity for a CPO contribution. Indeed, the caller's continuation in line 12 seems to be retrospectively constructed as a continuation of a hearably complete utterance. After a further delay on 13 the CPO comes in with an informational question about the son's age.

Questions of this kind are highly relevant to both the bureaucratic job of the helpline (collecting information for possible referral - the CPOs note down information of this kind) and to understanding the nature and severity of the putative offence. Note, however, that the question does not display the CPO's perspective on the report (assessing it as important, say, or trivial). Note also that the caller seems to treat the question as at least potentially an indication that the CPO is developing some line of 
action. His 'can I j's tell you what it is first of all' suggests an orientation to the 'yet to be established' nature of the problem to be addressed. ${ }^{9}$

Again, these features suggest that the concern construction is being treated as a prefacing move. The concern construction projects a multi-unit turn that develops a telling of the abuse report. ${ }^{10}$ During the course of this telling, assessments or other action initiations are likely to be less relevant. The CPO waits for the concern construction to be unpacked into a telling without coming to either a premature termination (which might cut off important further material) or a premature judgement (which might need to be changed in the course of the call). ${ }^{11}$ Where questions are asked they can be seen to be elaborating details of the current narrative telling ('how old is your son' - 15) or checking understanding ('he wasn't one of the five' - 41).

We will take one more example of the canonical form of concern construction as a preface for a multi-unit telling.

3. WO Gran abuse worries

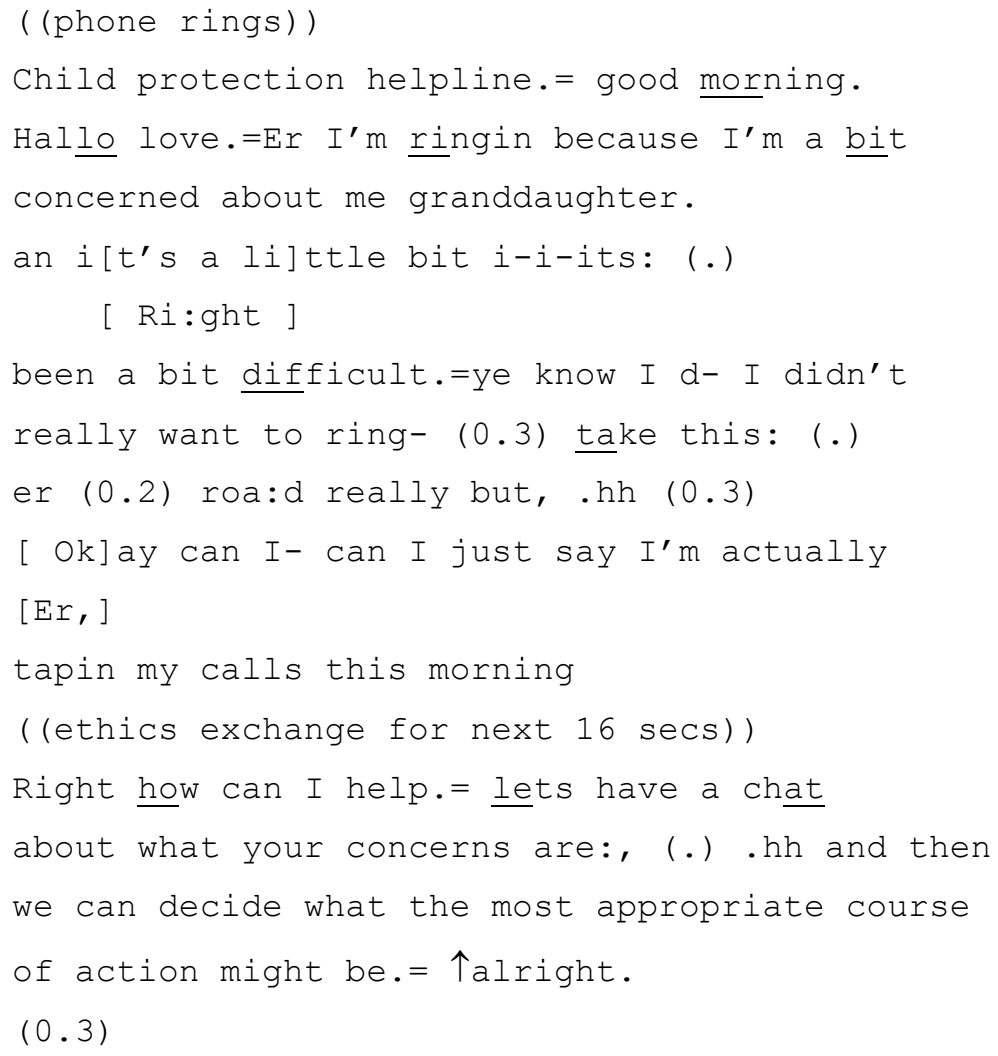




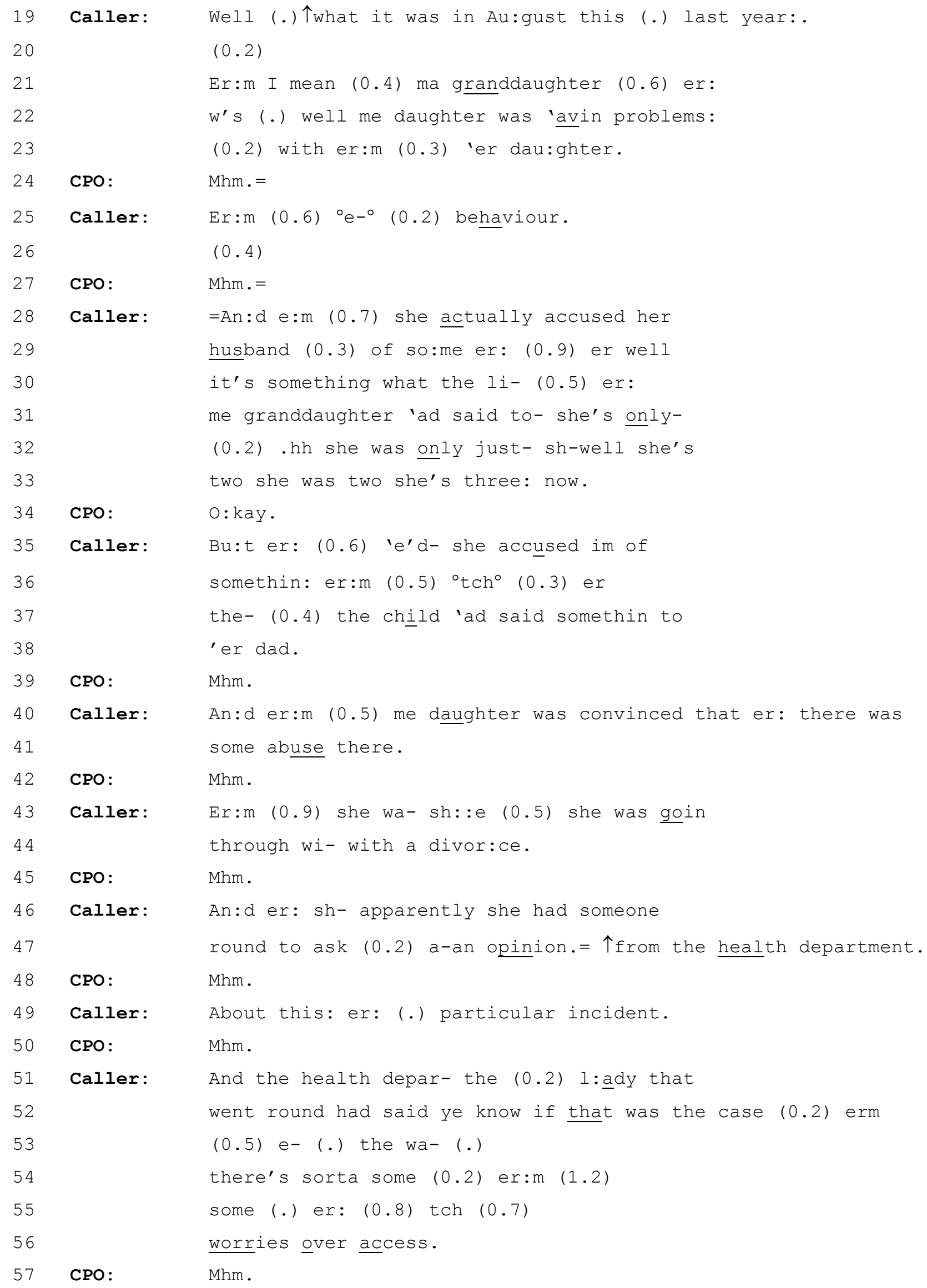


Note again that the caller starts with a concern construction ('I'm a bit concerned about me granddaughter' 2-3). The caller constructs her concern as the cause of the call.

Note also that after the ethics exchange the CPO follows the 'how can I help' with a latched 'lets have a chat about what your concerns are'. That is, in this case the CPO restarts the RFC sequence with a concern construction. What is projected is specifically a 'chat' about 'concerns' that will allow a decision about the appropriate course of action. This provides further and more explicit confirmation of the role of concern constructions in projecting a telling. In this case the telling is glossed as a chat suggesting that the telling will be collaborative and informal (cf. Antaki, 2000). This occasions an extended narrative from the caller. As in other examples, the CPO refrains from turns that assess, or terminate, or cut across this narrative in other ways. ${ }^{12}$

So far we have focused mainly on concern constructions of the form 'I am concerned about $X^{\prime}$. However, we have already seen that the CPO construction in Extract 3 uses concerns rather than concerned. The likely reason for this is that 'concerned about $\mathrm{X}$ ' involves naming or characterising the $\mathrm{X}$ in some way. At this point in the call the CPO is unlikely to have sufficient information for naming or characterising. More importantly, naming or characterising the $\mathrm{X}$ at this stage may unhelpfully influence the unfolding of the call or require repair from the caller. The formulation of callers' 'concerns' avoids either of these problems. By asking about the caller's concerns it is left for the caller to spell out the nature and significance of these concerns.

In the following call we can see the caller using concerns at the start of the RFC sequence. Rather than being 'concerned' about something, the speaker identifies 'concerns' as objects.

\section{HC kissing with tongue}




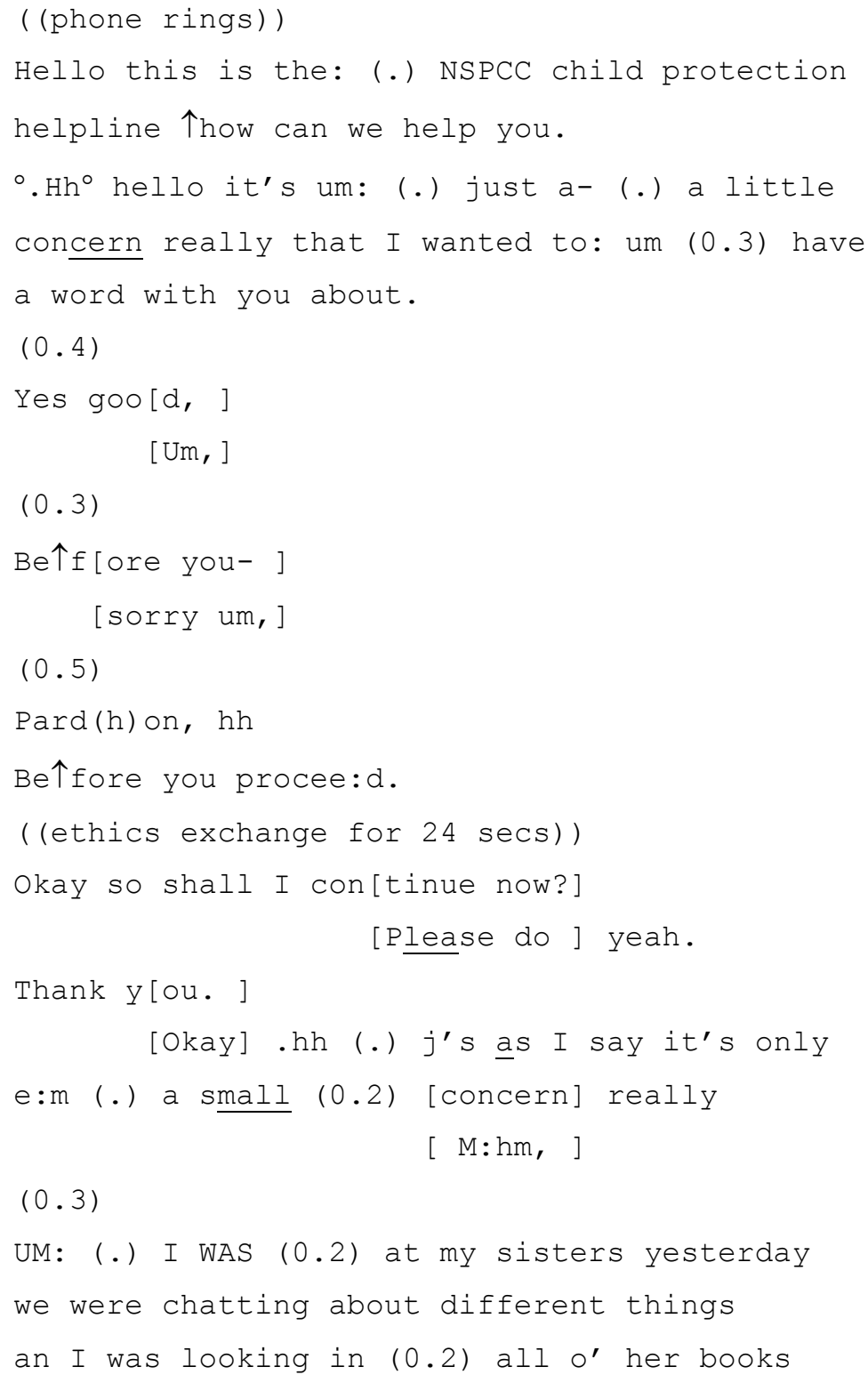

A key difference between 'concern' and 'concerned' is that the former does not require an object of concern to be delivered immediately. In Extract 4, for example, the caller starts the RFC with 'just a little concern' (lines 4-5) and then, after the ethics exchange, restarts the RFC with a 'small concern' (line 21) but the object of concern is deferred until later in the RFC after considerable background has been filled in.

We can see one reason why this separation of concern and object if we track through the RFC. The 'concern' (which is children using their tongues while kissing their parents) is about the caller's own daughter, her friend's two daughters, and the daughter of a friend of the friend. Deferring the object of concern allows these various 
persons to be introduced as part of a narrative of discovery. Using this form of concern construction breaks the syntactic link between the speaker's state and the object, thus providing for more narrative flexibility. In the next section discussing CPOs' constructions we shall see this flexibility in action.

\section{CPO Opens with Concerns}

Even where the caller has not opened with a concern construction it is common for the CPO to use a concern construction early in the call. Take the following:

\section{WO Abusive friend}

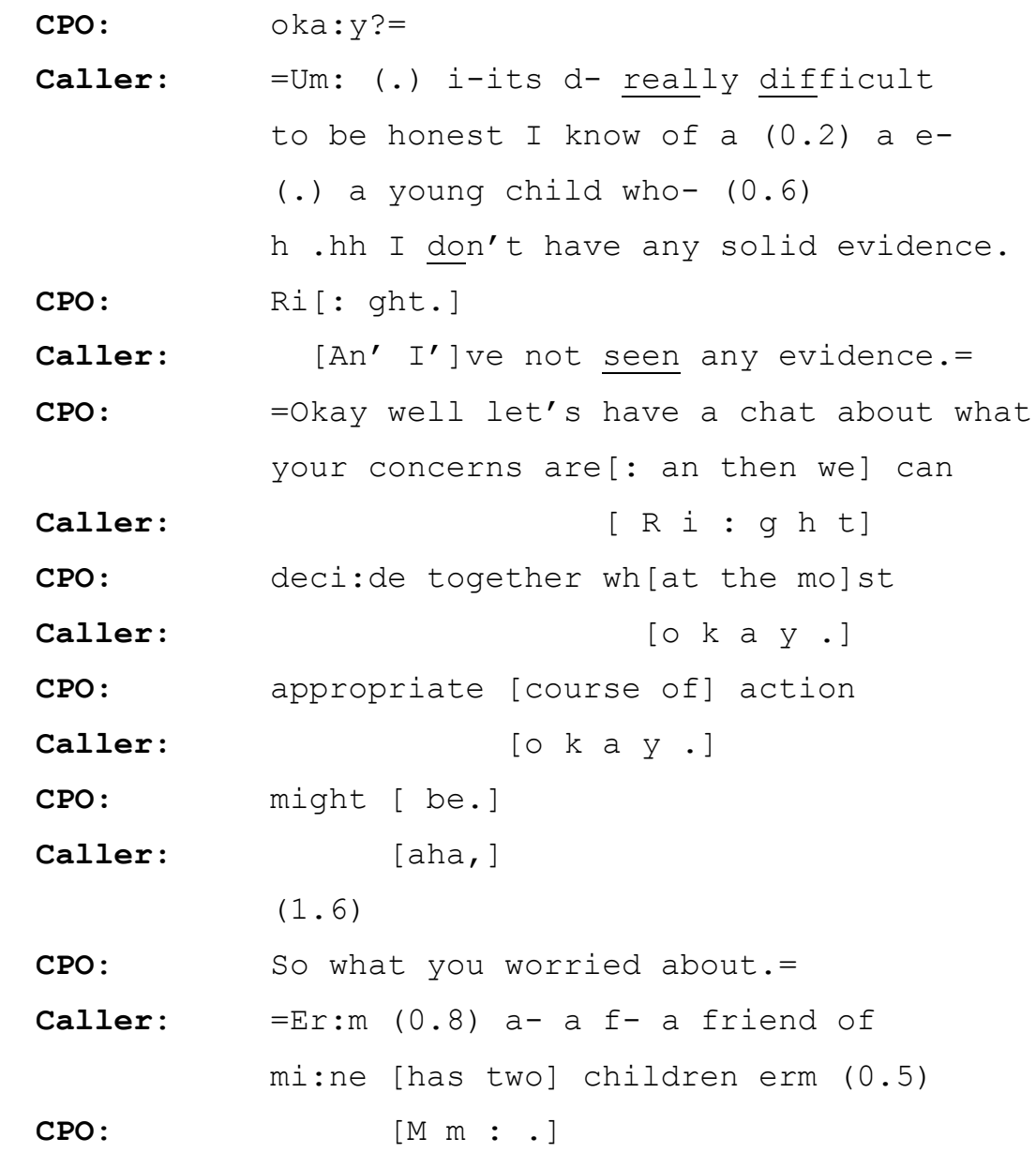

First consider the caller's trouble in lines 2-5. She prefaces her report as 'really difficult' and, having mentioned the victim, breaks off before specifying any abuse (line 4), instead emphasising the inadequacy of her evidence. The thing to highlight is what the CPO does. Rather than directly addressing any of the elements in the caller's RFC 
initiation, she uses the formulation: 'lets have a chat about your concerns'. In effect she cleans up the trouble and prepares for a relaxed and collaborative unpacking of 'concerns'. Although the CPO has mentioned concerns first, they are treated as something displayed by the caller. We can see here the CPO treating concerns as yet-tobe-unpacked problems to be addressed by the NSPCC through some course of action.

It is worth considering the specificity of CPO constructions. Although callers use 'concerns' (as opposed to 'concerned') in only $25 \%$ of examples, all of the CPO constructions are 'concerns' (or the similar 'worries'). We have already noted that 'concerns' breaks the syntactic link between the speaker's state and the object of concern. Attributing concerns prepares for the unpacking that comes next without requiring the $\mathrm{CPO}$ to characterise or name the object of concern. As we have indicated above, for the CPO to specify the object might well have an unwanted influence on the trajectory of the unpacking. Concern constructions minimise this problem.

\section{Reporting Reporting}

So far we have been developing an account of concern constructions as an element in a specific reporting practice, in particular as a way of projecting the RFC sequence as well as specifying the caller's stance to that sequence. We have suggested that they have a practical role in calls to the NSPCC. Another line of evidence for this considers calls where the caller presents as an intermediary reporting the reports of others. If concern constructions are an element of a specific reporting practice we can ask how far they are a stylistic feature of the way callers talk to CPOs, and how far they are part of the pragmatics of reporting another's concern.

In the following call the caller is reporting a report of a report of abuse.

6. BN Friend of a friend

1 CPO: Hh yes: how can I help.=

2 Caller: =Em: (.) a friend of mine rang me 


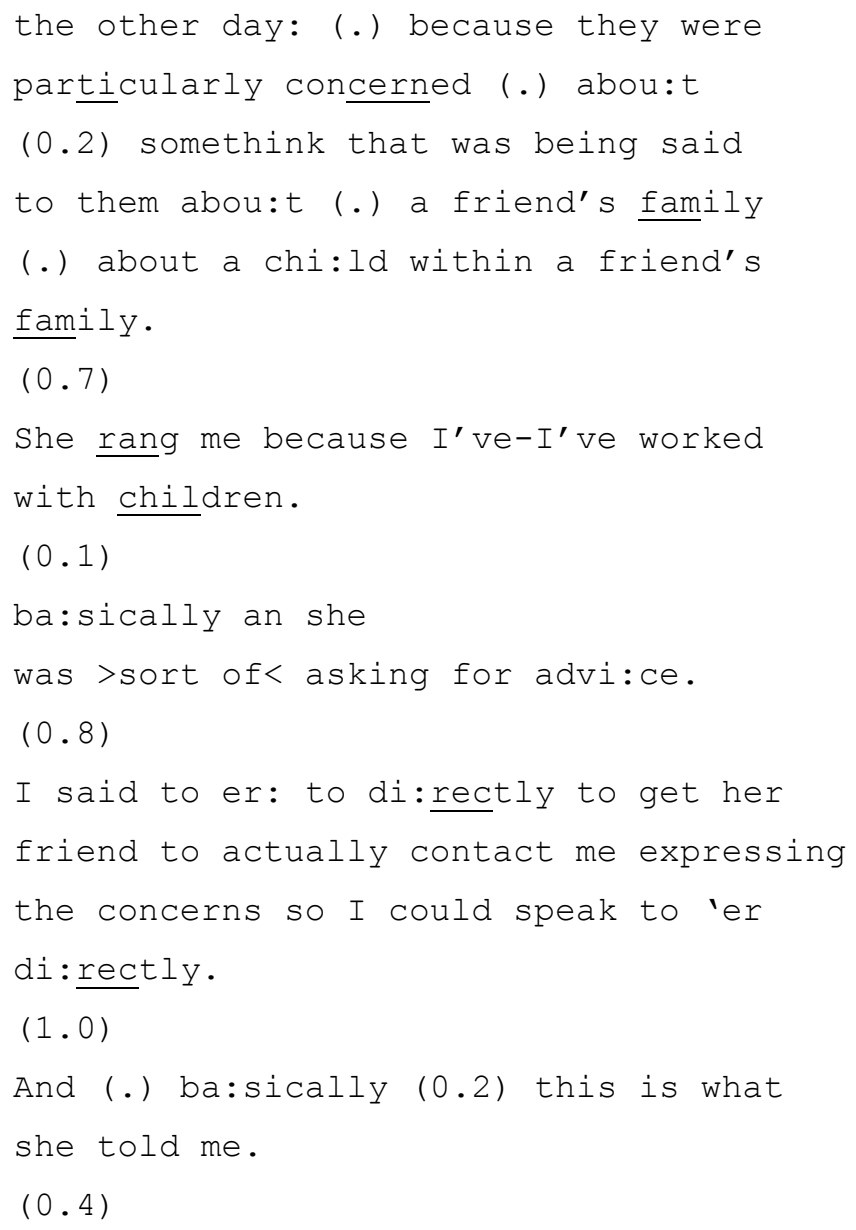

Note first the way the caller formulates the friend who reported problems to her as concerned (line 4). That is, she does not report herself as being concerned, but treats herself as the relayer of the concern of another. Put another way, the caller in this case constructs her talk in a way that parallels the CPO, reflecting the pragmatics of what she is doing rather than her official title.

There is a complexity here that is worth considering. The caller uses concerned rather than the canonical CPO concerns form. We can make sense of this by considering the pattern of footing here (Goffman, 1979). Unlike the CPO, who is avoiding constraining and prejudging the object of concern, the caller is reporting concern and formulating its (reported) nature. The caller's version of the friend's concern is the only one currently available. 
Now consider the second concern construction (lines 17-18). This is part of a meta-formulation where the caller describes her practice of getting the informant to offer information. She constructs herself as getting her friend to 'express the concerns'. This displays a recipient focused sensitivity to the problems of assessing second hand reports. The concern construction allows her to formulate this without yet specifying the object of concern. The modification of the concern construction when reporting another speaker's reports is further evidence of its specific practical role.

\section{SOME INTERACTIONAL USES OF CONCERN CONSTRUCTIONS}

At this point, let us take stock and tease out some of the more general features of concern constructions in NSPCC calls, and as part of 'reason for call' sequences in particular. We will also start to offer some interactional reasons for the use of concerns constructions.

Concern constructions are positioned at the start of the RFC sequence. Both caller and CPO orient to the concern construction as projecting the unpacking of the basis of the concerns. This unpacking is developed over a series of mult-unit turns during which the $\mathrm{CPO}$ is most likely to offer acknowledgement tokens or ask follow up questions. If the caller does not open with a concern construction the CPO may draw on one, using it in an attributional manner.

What is the role of the concern construction in the RFC sequence? We suggest that it manages the caller's stance toward the abuse, and two epistemological asymmetries between caller and CPO. Let us spell this out.

\section{Concern Constructions Manage the Caller's Stance}

Concern constructions display the caller's appropriate attitude or stance towards the putative abuse. In this corpus topics of 'concern' are treated as serious, potentially damaging or upsetting. Conversely, and relevantly here, they are not produced as things 
that the callers feel good about, are entertained by, or get pleasure or sexual excitement from. Put another way, there are two relevant noxious categories here; abuser and busybody. Elements of the concern construction manage the caller's separation from those categories.

Orientations to such contrasts are clear in the unfolding of RFC sequences. These orientations are displayed in a wide range of different ways in the narrative telling, and are comparable to the way narratives in emergency calls can manage issues of this kind (Zimmerman, 1992). CPO's may explicitly orient to the speaker's stance in a way that might be glossed as empathetic, as in Extract 1 above:

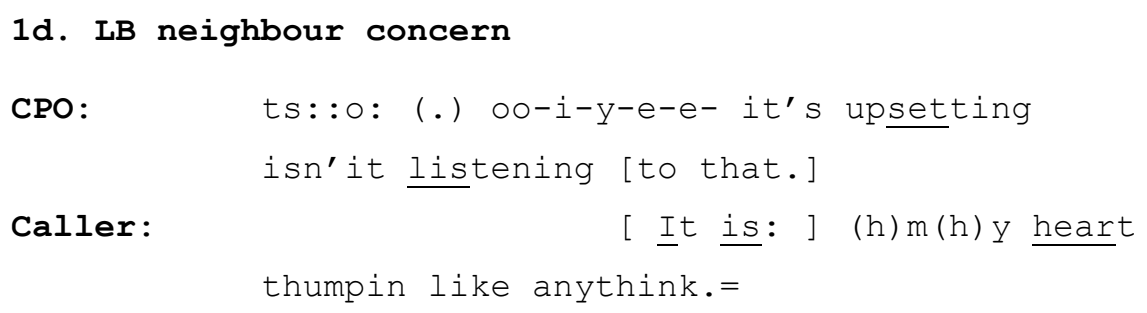

A full study of the way stance is displayed in RFC's must be reserved for another paper. However, the concern construction invokes that stance right at the outset and in an explicit manner. Note that both caller and CPO's use of 'concerns' does this. By constructing the caller as having 'concerns' and 'worries' the CPO displays a first assumption that the call is appropriately motivated.

\section{Concern Constructions Manage Asymmetry}

Concerns constructions orient to, and manage, two epistemological asymmetries. On the one hand, the caller knows about the particular events and actions that they are phoning in about and the CPO does not. The CPO is dependent on that knowledge. On the other, the CPO knows about the procedures of child protection work, the policies of the NSPCC, what reports are appropriately actionable and so on. A referral will not be made unless the CPO assesses it as appropriate. 
In projecting the RFC as unpacking concerns, the construction orients to these asymmetrical relations. By not starting with an assertion of the problem the caller lets the child protection appropriate status of what will be reported be decided by the CPO. The CPO is treated as the person who knows about child protection, signs of abuse, social services and so on and can decide on appropriate actions. In this sense, the organization of the interaction is similar to medical encounters where patients construct accounts of symptoms etc, which avoid prejudging their doctorability (cf. Gill, et al., 2001; Robinson, 2001; Silverman, 1987). By prefacing the RFC with a concern construction the caller prepares the way for a collaborative telling where the action worthy nature of the information can be assessed by the CPO.

From the point of view of the $\mathrm{CPO}$, the concern construction provides a basis for taking the abuse claims seriously, without either assuming or questioning their truth or appropriateness for the helpline. In this way they offer a special kind of neutrality. Concern constructions head off potentially troubling sequences where the caller asserts the existence of some abuse and the CPO then asks the basis for that knowledge (a case of this kind is seen in extract 13 below). Such sequences might suggest rather more disaffiliative doubt or scepticism, as opposed to the collaborative coming-to-a-view that results from unpacking concerns.

\section{FURTHER FEATURES OF CONCERN CONSTRUCTIONS}

The above features of the management of asymmetry are mainly provided by the concern construction's role in projecting a telling sequence where the status of the abuse is not prejudged. However, from a discursive psychological perspective we are particularly interested in the way the specific design of the concern construction contributes to the business of the calls. One way of thinking about concern constructions is that they index a state of affairs to the speaker. Thus the speaker has concerns and 
they are about something - this suggests broad classes of trajectories for the call. One trajectory focuses increasingly on the object - an abused child, an attack or incident, and its features. Such calls become less and less about the caller and more and more about features of persons and events (bruises, addresses, family relationships) that will be needed for social services or the police to follow up on the call. An alternative trajectory focuses increasingly on the caller and their psychology. This will consider worries, anxieties, misunderstandings and misperceptions and may involve reassurance. By using this construction the speaker projects the possibility that the concern may be misplaced, misunderstood, etc or that they are well founded, accurate, and so on. These contrasting trajectories are closely related to the epistemic asymmetries noted above where the caller knows about people, actions and events and the CPO knows about policy, child protection, criteria for referral and so on. The concern construction orients to the wide range of different outcomes that can result from this asymmetry.

Take the call in Extract 1 above. As the call develops it is increasingly focused on information about the various parties: ${ }^{13}$

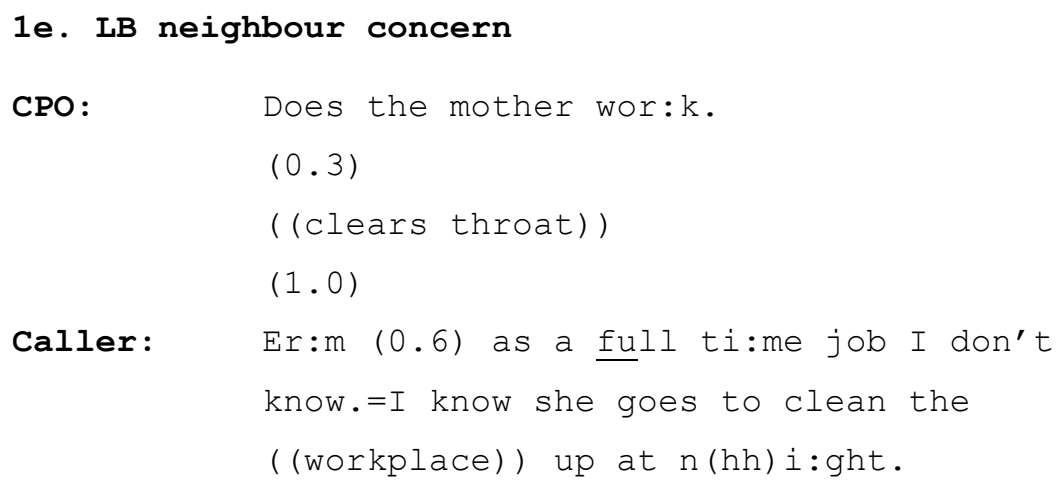

This call is followed by a referral to social services.

In contrast, the call in Extract 3 does not result in a referral to social services or the police. Instead there is a (sympathetic) focus on the caller's lack of evidence and the lack of justification for the their assumptions. This extract comes from 12.50 through a 25 minute call. 


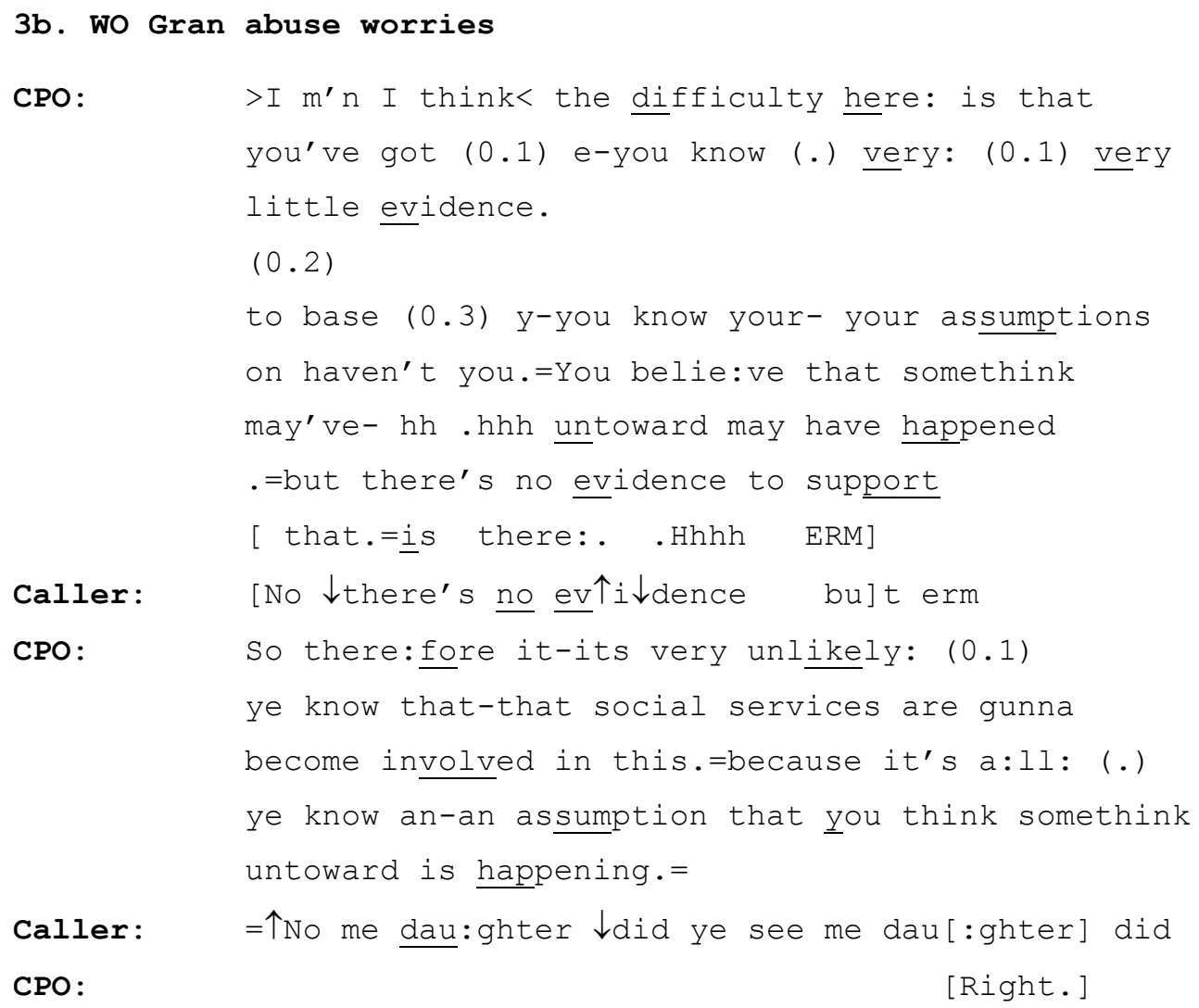

Note that concern constructions can coherently unfold in either of these trajectories. With Extract 1d the call has focused on what the caller is concern about. With Extract $3 b$ the call has started to focus on the caller's psychology - their assumptions and ill-founded beliefs. Note that the CPO here is not casting doubt on the caller's sincerity, their genuine concern; she specifically constructs the caller as believing that something untoward may have happened. Although this call does not result in a referral, the CPO suggests a range of actions that the caller might take, as well as indicating what further knowledge might lead to a future referral.

\section{VARATION IN CONCERN CONSTRUCTIONS}

So far we have focused on concern constructions that have used the lexical item concern. However, we do not wish to overemphasise the semantics of this one lexical item. Although the terms concern, concerned and concerns predominate at the opening of the RFC there are other constructions, using other terms, that can do the same job (or at least a similar job). 
We have already noted that the items worried and worries appear to do similar work to concerned and concerns. In three cases CPOs use 'worries' as a second formulation after 'concerns'. We have discussed one of these in Extract 5 above, here is another:

\section{UV Woman in Café}

CPO :

((phone rings))

Caller:

.hh Hello you are through to the NSPCC?

CPO :

Hello em .hh I'm actually phoning (0.2)

f-for some advice regarding an incident that I

witnessed today.=

CPO :

=. hh okay that- that's fine we're happy to offer advice

( (moves on to ethics exchange and general statement of

NPSCC's practices for 35 secs))

So what I like to say to people is let's ta:lk

arou:nd the situation first (0.4) and work a way

forward (0.2) um: you know make a decision together

about what we're going to do about (0.3) your

concerns.

Caller: Yeah.

CPO: Is that alright with you.

Caller: Yeah: absolutely yes

CPO: Okay right okay otherwise we could find ourselves

Caller: half way down the road (0.3) you know (.) going off in different directions.

CPO :

Mhm [Mhm. ]

[.hh ] ${ }^{\circ}$ tch ${ }^{\circ}$ okay so y- you (0.2) something you've witnessed today has worried you:.

(.)

CPO: .h[h h $]$ u:m (.) can you just tell me a little bit

Caller: [Yeah]

CPO: about that.

Note the way that the caller is treated as having called on the basis of concerns (lines 13-

14), despite having not mentioned concerns in the opening of the call. Having established this basis for the call the CPO asks a specific question about the caller's worries (line 30-34). Again, the caller has not mentioned worries at this point. 
In effect, what the CPO has done is produce a question that has a very similar prefacing status to the standard concern construction. The question formulates the stance of the caller (worried) and the object that generates it is only named in the most general terms (something). The question projects an answer that will unpack the worry in the caller's own terms (and this is what happens as the call progresses). The CPO can ask this question in this way at this point in the call because they already have a formulation from the caller about the reason for call. ${ }^{14}$ It is not available as a standard CPO first question.

The lexical item 'worries' can work in the same way as 'concerns', then, taking the form of an object to be unpacked ('can you tell me a little bit about that'). Like concerns it explicitly presents the caller's appropriate stance to the abuse and the act of calling - worried rather than confused, worried about what is happening rather than trying to get someone in trouble. Like concerned, worried presents the caller as yet to come to a definitive view of the object of worry, that allowing that status to be established collaboratively with the CPO.

Our final example of an equivalent object highlights the way other psychological descriptions can stand in for concerned or worried. In the following call note particularly the display of emotion in line 7.

\section{JK stray girl}

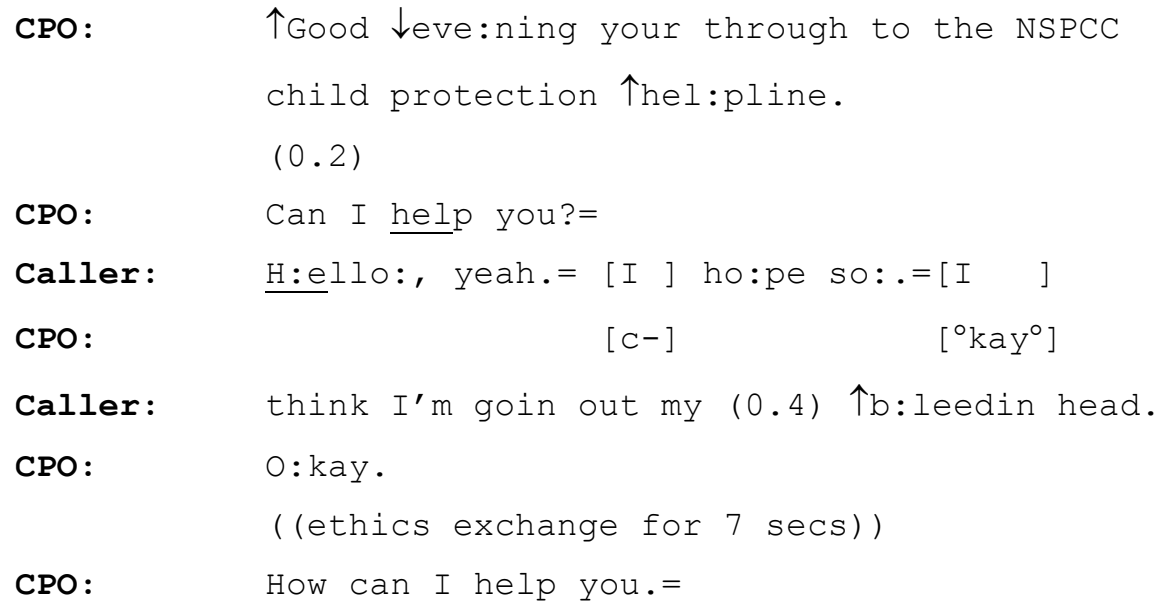




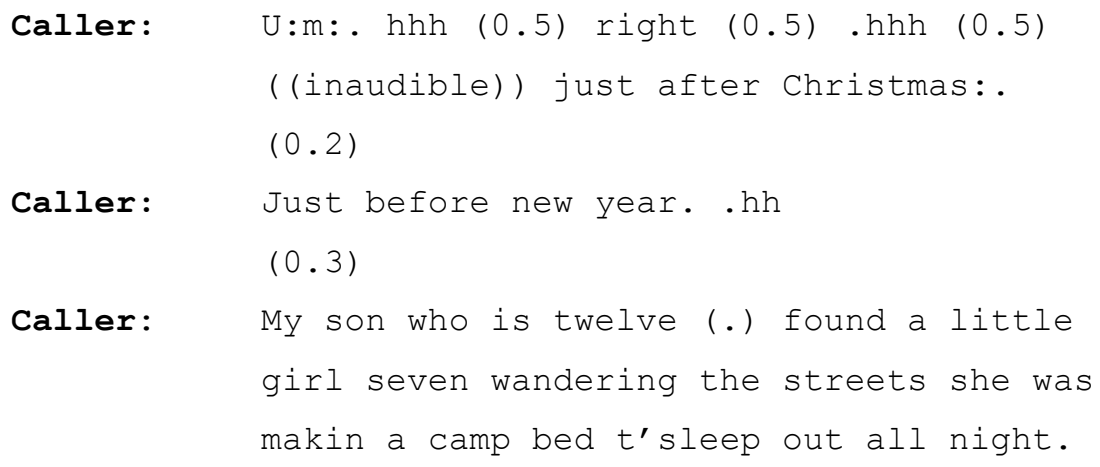

The 'going out of my bleedin head' construction projects what is to be unpacked but does not yet describe or categorise it. Like a concern construction it indexes the speaker's state and something (as yet unspecified) in the world. Like a concern construction it displays the caller's stance to the object. Like the concerns variant it defers the object of concern. It is different, however, in providing a strong indication that the issue is both severe and ongoing. This indication comes not just from the 'going out of my bleeding head' construction, but also from the delivery of the talk and the interspersed sighs and breathiness particularly in lines 2 and 3. The 'mental state' is not just described it is displayed. The point, then, is that this opening performs much of the same (but not precisely the same) business as the concern construction, but with a particular inflection.

Let us consider one final example, which is superficially similar, but has some different elements. This is a RFC initial construction that invokes a problem.

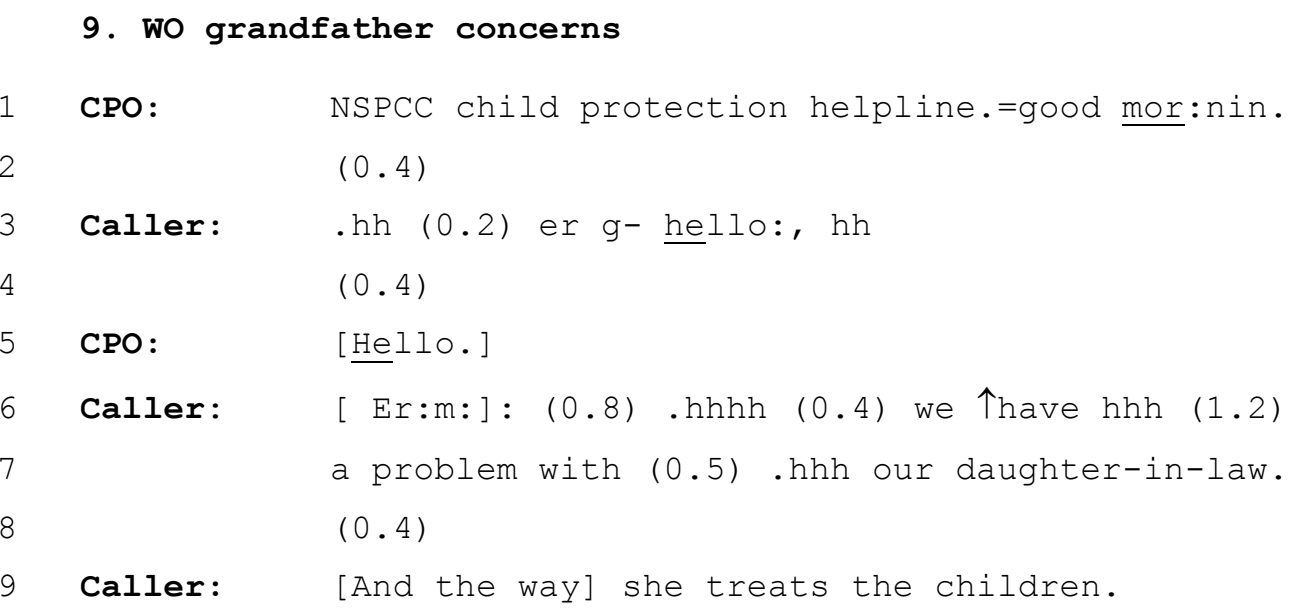




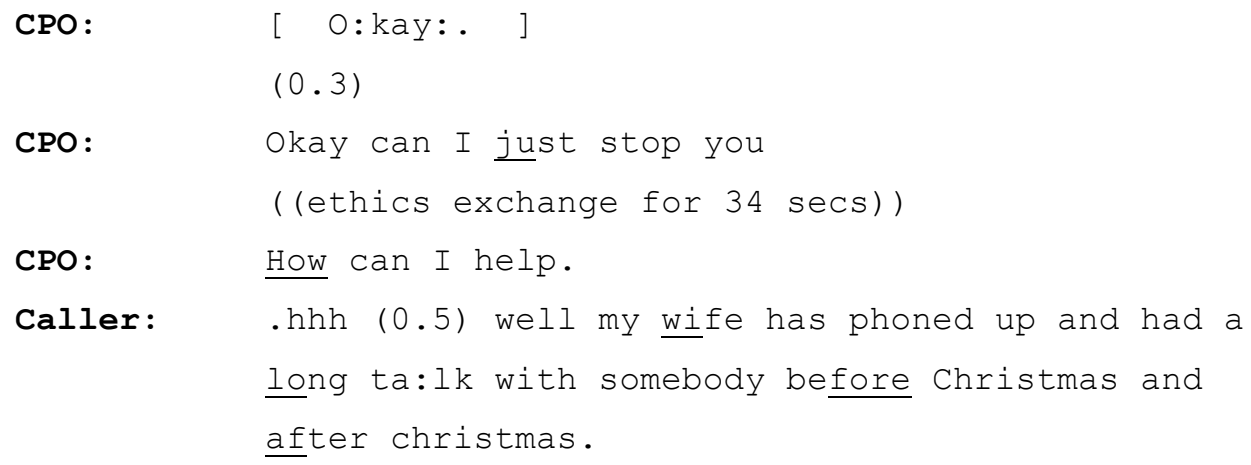

As with more standard concern constructions, the problem construction on line 7 projects the unpacking of a problem. It also displays the caller's stake in the issue (a problem rather than a source of pleasure, something to be sorted out rather than a way of getting someone into trouble). The description 'problem' also projects a potential task for the call - to solve or help with the problem ${ }^{15}$. It therefore shares some features with more standard concern constructions.

Where 'problem' is different from 'concerns' is that it suggests something already crystalised rather than yet to be established. The caller is not concerned that there might be a problem; there is a problem, and he needs help with it. It may well be that this is related to the call being one of a series. It is noticeable that directly after the ethics exchange the caller makes reference to a prior call (which involves a 'long talk'), and it may well be that this provides a justification for the more crystalized problem construction. The previous call may have started with a concern construction and now, following the crystalization of a particular problem suitable for NSPCC attention, the second call can start with a problem construction. Without a further analysis of calls in series this can only be a speculation at present. The organization of the call, which contains some canonical and some deviant features, therefore provides further support for our general claims about concern constructions. 


\section{DEVIANT CASES}

In this last analytic section we will consider deviant cases, focusing on calls

without concern constructions at the opening of the RFC. ${ }^{16}$ There are 3 classes of these:

1. Calls where the caller is performing a different action to reporting abuse such as asking for advice or complaining;

2. Calls where the caller is speaking on behalf of someone else;

3. Calls from professionals such as caseworkers or health visitors.

We will be particularly focused on whether these deviant cases support our general account of the role of concern constructions in the RFC. The absence of the canonical concern format can be seen as linked to the different activity that is being done. As well as these 'standard' deviant cases we will briefly consider a single call that is rather different from the rest of the corpus.

\section{Alternative Actions}

The central role of the NSPCC Helpline is often treated as the referral of claims about abuse to the relevant authorities. As we have seen, CPOs assess the information provided in such calls and make a decision on whether to make a referral or offer some other kind of advice or reassurance. Nevertheless, it gets a very wide range of different kinds of calls. It is not always easy to tell what the call is going to be about from the outset.

Our analysis of concern constructions suggests that they will be appropriate for some activities, but less so for others. Take advice for example. Advice might be requested in a 'concerns' environment when the object of the advice is itself contentious or to be established, or requiring institutional confirmation before action is taken. Extract 7 is an example of this kind, where the CPO repackages what is going on using a concern construction. At other times, advice might be requested where the caller claims 
an identity that warrants knowledge of particulars. Moreover, in some cases the callers may not be requesting action from the $\mathrm{CPO}$, but eliciting information to assist with their own action (although their own action may turn out to be reporting information to the CPO for their action). To illustrate:

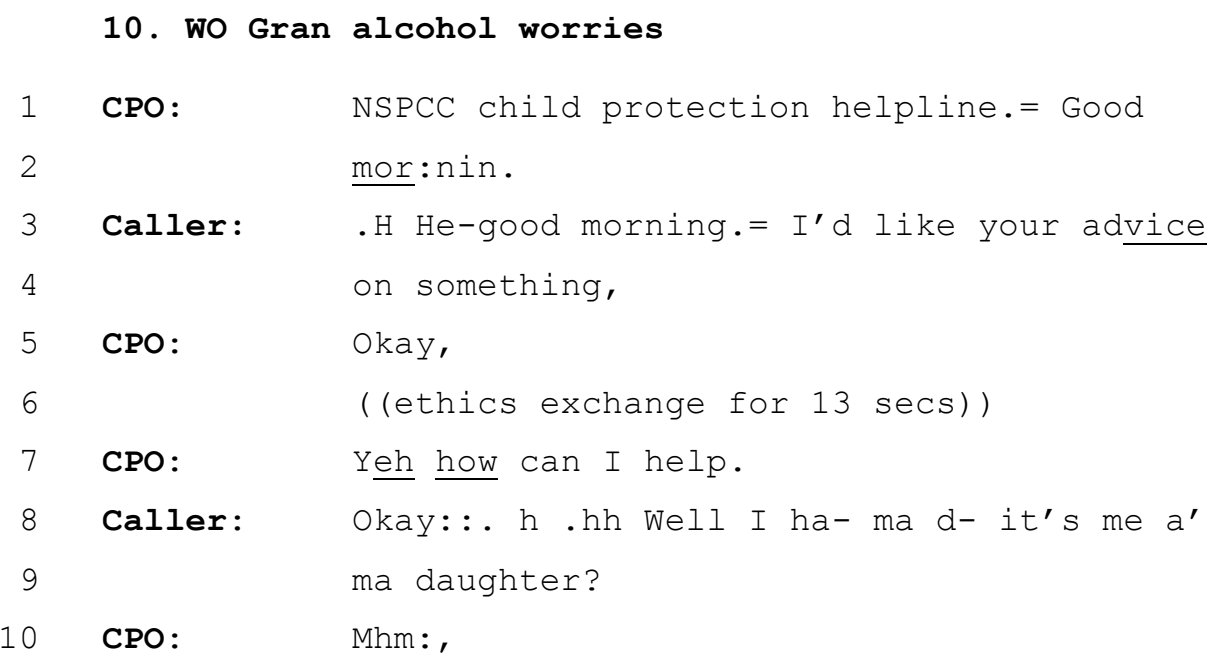

Advice openings such as this are similar to concerns openings in that they project a report. The 'something' mentioned in line 1 in extract nine is unpacked in considerable detail over the next few minutes of call. They are different from concerns openings in that do not project a situation where the nature of the object of advice is to be jointly determined with the CPO. In this case, the mother is detailing a set of events that happened to her daughter, and 'mother' is clearly a knowledge entitling category with respect to daughters. ${ }^{17}$

A further small class of calls doing alternative actions involves the caller making a complaint. In two cases in the corpus the call evolves into a complaint about the role of professional groups (a school, social services) rather than remaining a simple report of abuse. Again these calls mark a soft boundary to the category of abuse reporting calls. To save space we will not discuss them here. The general observation is that advice and complaint calls often draw on a more definitive version of the problem. They may involve advice on something or a complaint about something, where the request for 
advice or the complaint might be disrupted by a joint establishing of the nature of that something.

\section{Calling on Behalf of Another Person Reporting Abuse}

A second class of calls without concerns openings involve the caller speaking on behalf of someone such as a husband or father who wishes to report abuse to a child. They are different from calls reporting reports (as in extract 6) as the caller here presents herself as mandated or at least able to speak from another's point of view. These are complex cases, and in some respects mark out a rather open boundary of calls which are reporting $3^{\text {rd }}$ party abuse. However, the point of interest is why they rarely use concern constructions.

In the following call the caller presents as calling on behalf of her husband.

11. AD husband abused

CPO :

[ Ri:ght. ] Ri:ght.= 


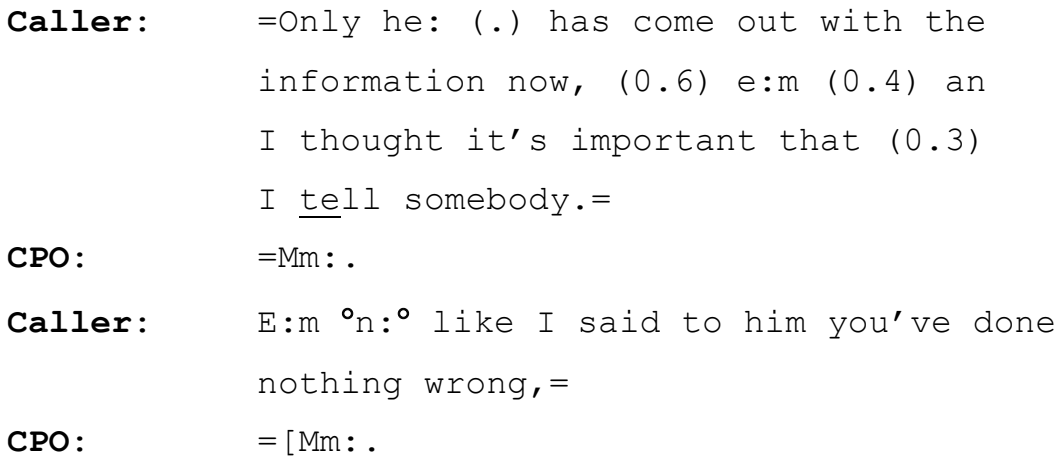

In this case, by presenting as speaking on behalf of another, the caller implies access to their perspective. That is, that perspective is not a matter of inference, a matter to be concerned about, where concerns could therefore be unpacked. However, the other person is not presented as having concerns (as in the $3^{\text {rd }}$ party reports); rather they are someone with relevant and potentially significant information. It is probably significant with this call that the husband may have a double status as a victim of earlier abuse and a possible abuser. It may also be significant that the caller presents as having rung before (cf. Extract 9 above). This all adds a complexity that would be difficult to package into a simple concern construction.

\section{Professional Callers}

There are a number of reasons why callers speaking from professional categories rarely use concern constructions. First, such callers may be treated as entitled to know about abuse in a way that lay callers may have to earn such an entitlement (Potter, 1996; Sacks, 1992; Whalen \& Zimmerman, 1990). So they do not present concerns to be jointly unpacked. Second, and interestingly, their stance to the victim can be primarily institutional; they do not need to implicate psychological concern as a motive for calling or to manage their stake as someone who cares. They have an occupational membership that cares for children. Third, and conversely, their institutional stance to the victim works against various interests that callers with personal relationships to the victim 
(estranged partner, neighbour) might have for fabricating information or making hoax calls. These reasons make it less likely that they will use concern constructions.

Let us take an example. Note the way the caller describes their identity as a 'health visitor' very early.

12. JX Health visitor

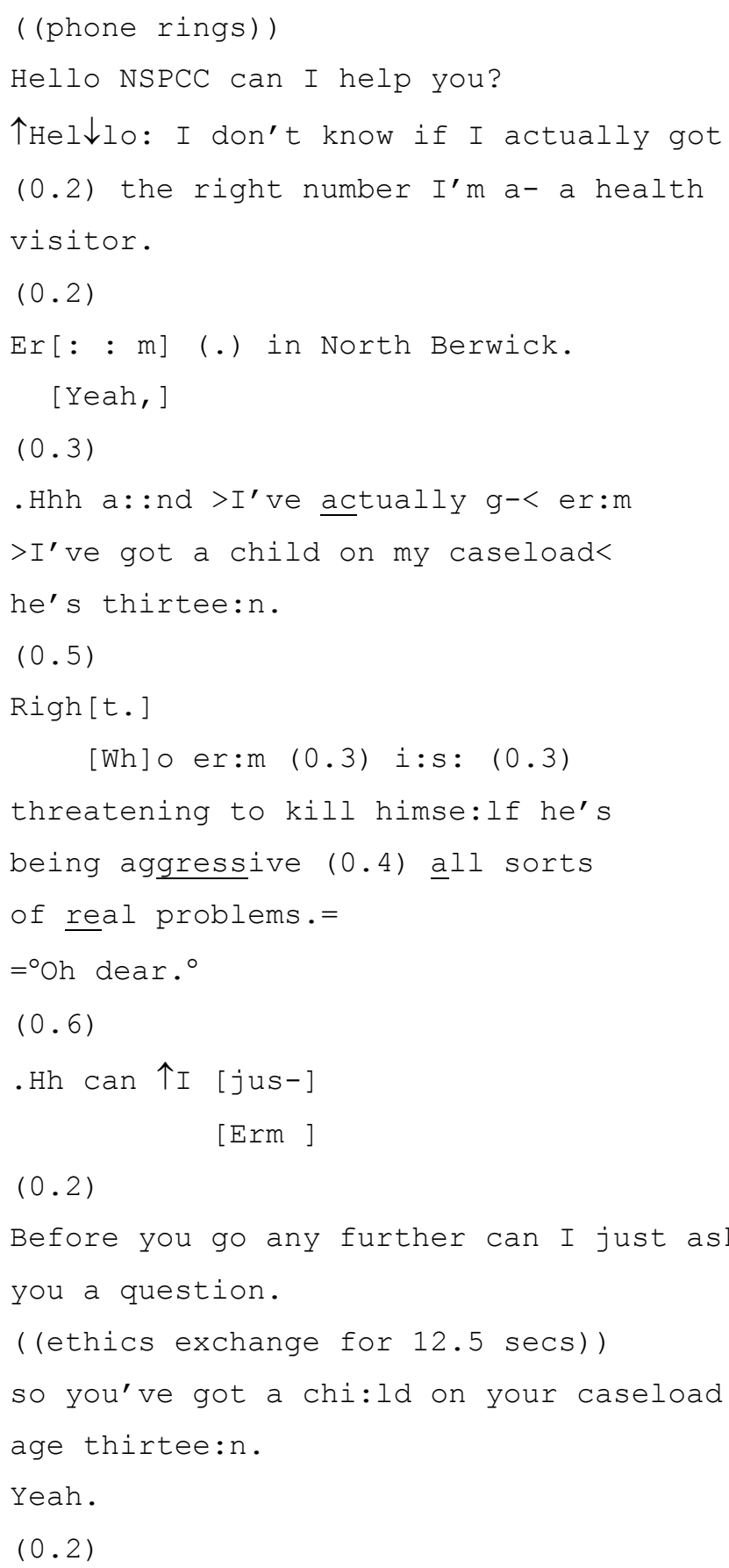

After noting some uncertainty about the right number, the caller presents as a 'health visitor' (lines 4-5). This presentation is followed by an organizational characterisation of 
the caller's relationship to the victim: 'I've got a child on my caseload' (line 11). Note also the way that after the ethics exchange the CPO repeats this organizational characterisation (line 27). The presentation as a health visitor goes with the absence of much of the asymmetrical unpacking seen in lay calls. The absence of concern constructions in these cases is further confirmation of the business that concern constructions do in the canonical case of a lay caller reporting suspected abuse.

We will end our analysis with a consideration of a single case where abuse to a third party is directly claimed by a non-professional caller.

\section{Potential Trouble}

We are not going to devote much space to this opening. At this point we will just make some tentative observations related to the absence of a concern construction. Our focus is on its departure from the canonical form, and the problems that departure might generate. The caller here opens the RFC with a definitive assertion that her friend has been sexually abused.

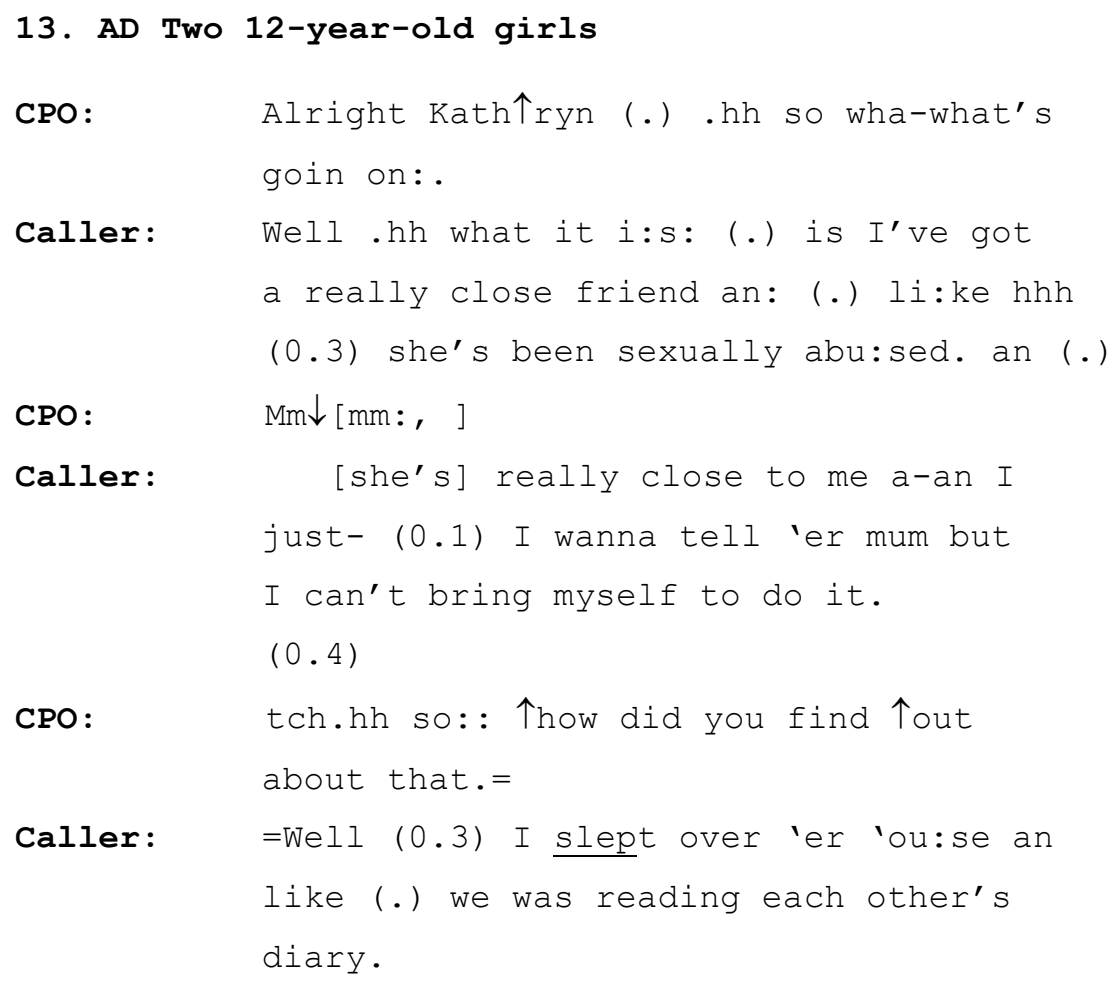


There are a range of departures from more standard forms here. In line 1 the CPO addresses the caller by first name (the caller gave her name in the opening before the ethics exchange). Also her question in lines 1-2 uses a more direct form of asking about events that presumes that something is 'going on' rather than the more cautious, and more common, 'how can I help'. In this way the CPO may have occasioned the caller's early definitive assertion of her friend's sexual abuse, which is the least cautious opening of any of the calls in our corpus (lines 3-5). Asking about the evidence for, or basis of, an assertion of this kind may sound challenging or sceptical (Pomerantz, 1984). The CPO manages that problem by a question that presupposes the existence of the claimed abuse, probably lessoning the potential for sounding sceptical (lines 11-12) but moving away from the more usual opening neutrality with respect to the status of claims. ${ }^{18}$

It is likely that these departures are, at least in part, a feature of the delicacy of the CPOs' approach to child callers, and perhaps the different expectations of child callers. Plainly these special features will deserve further study.

\section{DISCUSSION}

We will summarise our observations before going on to consider broader implications. Concern constructions are a collection of similar constructions that are used to do similar work in projecting an unfolding description of potential abuse. They can be produced by caller ('I'm concerned about x') or CPO ('lets have a chat about your concerns'). Although the lexical item 'concern' (in the variants concerned and concerns) predominates, both caller and CPO can use 'worries' (or worried). As we have shown above, other constructions such as 'I'm goin out of my bleedin head' can do a very similar job. For simplicity, and to mark the predominance of the use of the term concern we have retained the description 'concern construction' for these variants.

Concern constructions have a range of features: 
1. Concern constructions are oriented to as a pre-move in the caller's reason for call. They project the unpacking of the concerns in a multi-unit turn.

2. This unpacking is oriented to the institutional role of the helpline in collecting evidence and acting on that evidence. This reflects an asymmetry of knowledge where the caller knows something and the CPO does not.

3. This unpacking allows the CPO to collaboratively constitute the nature of the action/event/abuse (in a way that is appropriate to the helpline) or not, to and warrant that the action/event/abuse requires further action or not. This reflects an institutional asymmetry of knowledge where the CPO knows about child protection etc. and the caller does not. In interactional terms it removes the requirement for potentially disaffiliative actions on the part of the CPO, such as asking for the basis of claims that have already been made.

4. Concern constructions provide CPOs a way of taking abuse claims seriously while not having to presuppose their truth. Both caller and CPO can treat the claim as serious and appropriately motivated but yet to be established as something to be acted on. ${ }^{19}$ They provide a special kind of neutrality.

5. Concern constructions display callers' stance on the subject of concern. In a simple way, they are concerned not pleased, entertained, and so on.

It is worth briefly comparing our findings with Baker et al.'s (2001) study of a software helpline. In their materials the RFCs are not opened with concern constructions. The examples they provide show the caller either launching directly into a narrative formatted RFC:

C: erm I've installed (.) office ninety seven?

$(0.8)$

.hh and (.) erm my negative figures are different

(from Baker et al., 2001: 51) 
or prefacing a narrative with a problem construction:

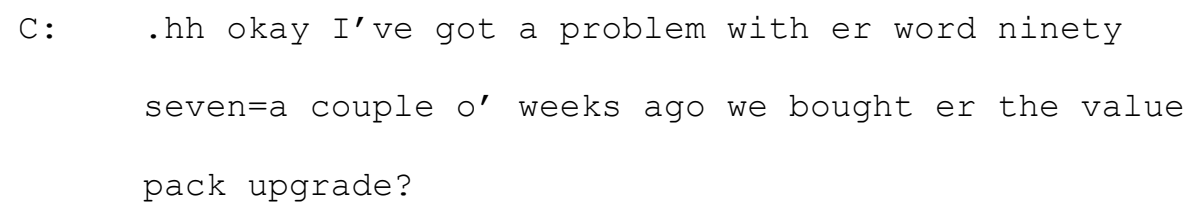

(from Baker et al., 2001: 51)

It is tempting to speculate that the difference is due to the particular psychological delicacies and dangers of reporting abuse as compared to asking for help with a computer problem. However, there are a range of other pragmatic differences (for example, the NSPCC CPOs are not, typically, solving a problem for the caller). Most significant may be the fact that the callers in the Baker et al., (2001) study have been prescreened - they are passed to technical support after being already ratified, in a preliminary way, as having an appropriate problem. In this they are similar to the RFC openings in Extracts 9 and 11 above.

Finally, let us return to our broader issue of cognition and interaction. So far we have tried to show how the interactional role of concerns constructions. In this final part of the paper we will stand back and consider how the 'psychological' language in the concern construction contributes to this role.

One of the central themes in discursive psychology has been the way descriptions of 'mind' and 'reality' are assembled in and for action (Edwards, 1997; Potter, 1996). Descriptions of this kind are treated as inferentially linked; mind to reality and vice versa. This linking is played out practically in the NSPCC calls. Consider 'I'm concerned about a child that lives next door'. The concern construction implicates the state or stance of the speaker, but also suggests something about the world: there is something to be concerned about. This double relation is part of what makes it effective as a preface for unpacking. As we have noted, the different trajectories of the calls may come to focus on the speaker (and their understandings, assumptions, expectations, 
confusions and so on) or the object of concern (and its features, location, duration and so on).

The issue we wish to highlight is the status of concern as a cognitive, in the head phenomenon. What is wrong with saying that a caller has a concern (or worry) and thus calls the helpline to report that concern, which is then explored in detail with the CPO? This is certainly a potentially useful practical gloss on what is going on, for workers at the helpline for example. However, we want to be cautious about adopting it as a technical account as part of analysis, and particularly cautious about the implied cognitivist assumption that action is driven by mental processes and mental states in this account. The cognitivist account that has the concern as an 'in the head' feature of the actor is not easy to square with the widespread variation between the cautious concern constructions that callers use in openings and the often more definitive constructions they offer at other stages in calls. Nor is it easy to square with the widespread attributional use of concerns and worries constructions in the CPO's early turns.

What we see in this material is a psychological construction being used practically, and jointly by caller and CPO, to do institutional business. What makes the constructional psychological? In interactional terms we suggest grammar ('I'm concerned') and attribution ('let's have a chat about what your concerns are'). This is a construction that starts with the speaker, from their point of view as a reporter on events, and provides an account for reporting on events. Concerned is part of a relational construction ('concerned about x') and it provides the speaker's stance ('concerned', not happy, or indifferent, or aroused). Alternatives such as 'worried' have a similar quality (as do displays of being upset about something). From this perspective the concern construction can be viewed as a resource for action; it is employed by both caller and $\mathrm{CPO}$ to manage the delicate interactional pragmatics of reporting abuse. Put another 
way, it is more sensible to ask what the role of the concern construction is in NSPCC calls than to ask whether the callers really are concerned or not.

From this point of view the helpline, as an institution, is characterised by specifically 'psychological' business and further, that this business partly constitutes its form. When we return to the London NSPCC call centre it is impossible not to hear 'concern' as a pervasive currency as the CPOs field calls. We have no doubt that the business done on the helpline with 'concerned' (and 'concerns', 'worried' and so on) is a refinement of everyday psychological business, just as many of its conversational features are a refinement of everyday conversational organizations. ${ }^{20}$ Finding the roots of that business in everyday psychological practices will be an important project (see Edwards, 1997, Wiggins \& Potter, in press, for some pointers). More broadly, we hope that this line of analysis will help develop a discursive psychology of institutions. 


\section{REFERENCES}

Antaki, C. (2000). Two rhetorical uses of the description 'chat'. M/C: A Journal of Media and Culture, 3. http://www.api-network.com/mc/0008/uses.html

Baker, C., Emmison, M. \& Firth, A. (2001). Discovering order in opening sequences: Calls to a software helpline. . In A.W. McHoul \& M. Rapley (Eds). How to analyse talk in institutional settings: A casebook of methods (pp. 41-56). London; Continuum International.

Clark, H.H. (1992). Arenas of language use. Chicago: University of Chicago Press.

Coulter, J. (1990). Mind in action. Oxford: Polity.

Coulter, J. (in press). Language without mind. In H. te Molder \& J. Potter (Eds). Talk and Cognition: Discourse, Cognition and Social Interaction. Cambridge: Cambridge University Press.

Danby, S., Baker, C.D. \& Emmison, M. (in press). Four observations on openings in calls to kids help line. In Baker, C.D., Emmison, M. \& Firth, A. (Eds). Calling for Help. Cambridge: Cambridge University Press.

Drew, P. \& Heritage, J.C. (Eds.) (1992). Talk at work: Interaction in institutional settings. Cambridge: University of Cambridge Press.

Drew, P. (1995). Interaction sequences and 'anticipatory interactive planning.' In E. Goody (Ed.), The social origins of human intelligence (pp. 111-138). Cambridge: Cambridge University Press.

Drew, P. (in press). Is confusion a state of mind? In H. te Molder \& J. Potter (Eds). Talk and cognition: Discourse, mind and social interaction. Cambridge: Cambridge University Press. 
Drew, P. (1984). Speakers' reportings in invitation sequences. In J.M. Atkinson and J.C. Heritage (Eds.) Structures of social action: Studies in conversation analysis (pp. 12951). Cambridge: Cambridge University Press.

Edwards, D. (1997). Discourse and cognition. London and Beverly Hills, CA: Sage.

Edwards, D. \& Potter, J. (1992). Discursive psychology. London: Sage.

Edwards, D. \& Potter, J. (2001). Discursive psychology. In A.W.McHoul \& M. Rapley (Eds). How to analyse talk in institutional settings: A casebook of methods (pp. 1224). London; Continuum International.

Edwards, D. \& Potter, J. (in press). Discursive psychology, mental states and descriptions. In H. te Molder \& J. Potter (Eds). Talk and cognition: Discourse, mind and social interaction. Cambridge: Cambridge University Press.

Gill, V.T., Halkowski, T. and Roberts, F. (2001). accomplishing a request without making one: A single case analysis of a primary care visit, Text $21,55-81$.

Goffman, E. (1979). Footing. Semiotica, 25, 1-29.

Graesser, A.C., Gernsbacher, M.A. \& Goldman, S.R. (1997). Cognition. In van Dijk, T.A. (Ed.). Discourse as structure and process (pp. 292-319). London; Sage.

Heritage, J.C. (1997) Conversation analysis and institutional talk: Analysing data. In D. Silverman (Ed.) Qualitative Research: Theory, method and practice (pp. 161-182) London; Sage.

Heritage, J.C. (2002). Applied CA. Manuscript under submission.

Heritage, J.C. (in press). Cognition. In H. te Molder \& J. Potter (Eds). Talk and cognition: Discourse, mind and social interaction. Cambridge: Cambridge University Press.

Heritage, J.C. \& Sefi, S. (1992). Dilemmas of advice: Aspects of the delivery and reception of advice in interactions between Health Visitors and first-time mothers. In P. Drew 
\& J. Heritage (Eds.), Talk at work: Interaction in institutional settings (pp. 359-417). Cambridge: Cambridge University Press.

Heritage, J. and Lindström, A. (1998). Motherhood, medicine and morality: scenes from a medical encounter, Research on Language and Social Interaction, 3, 397-438.

Heritage, J, M.L. Sorjonen (1994) Constituting and maintaining activities across sequences: And-prefacing as a feature of questioning design, Language in Society, 23, 1-29. Hopper, R., Ward, J.A., Thomason, W.R. \& Sias, P.M. (1995). Two types of institutional disclaimers at the cancer information service. In G.H. Morris \& R.J. Chenail (Eds). The talk of the clinic (pp. 171-184). Hillsdale, N.J.; Lawrence Erlbaum.

Hutchby, I., \& Wooffitt, R. (1998). Conversation analysis: Principles, practices and applications. Cambridge: Polity.

Lynch, M. \& Bogen, D. (1996). The Spectacle of History: Speech, Text, and Memory at the Iran-Contra Hearings. Durham, NC: Duke University Press.

Lynch, M. \& Bogen, D. (in press). Oliver North's memory. In H. te Molder \& J. Potter (Eds). Talk and cognition: Discourse, mind and social interaction. Cambridge: Cambridge University Press.

Pomerantz, A.M. (1984b). Giving a source a basis: The practice in conversation of telling 'how I know.' Journal of Pragmatics, 8, 607-625.

Pomerantz, A. (1990/1991). Mental concepts in the analysis of social action, Research on Language and Social Interaction, 24, 299-310.

Potter, J. (1996) Representing Reality: Discourse, Rhetoric and Social Construction. London; Sage.

Potter, J. (1998). Cognition as context (whose cognition?), Research on Language and Social Interaction, 31, 29-44. 
Potter, J. \& Edwards, D. (in press). Rethinking cognition: On Coulter, discourse and mind, Human Studies.

Robinson, J.D. (2001). Asymmetry in action: Sequential resources in the negotiation of a prescription request, Text, 21, 19-54.

Ryle, G. (1949). The concept of mind. London: Hutchinson.

Schegloff, E.A. (1982). Discourse as an interactional achievement: Some uses of 'uh huh' and other things that come between sentences. In D. Tannen (Ed.), Analyzing discourse, text and talk (pp. 71-93). Washington DC: Georgetown University Press.

Schegloff, E.A. (1986). The routine as achievement, Human Studies, 9 (2/3), 111-152.

Schegloff, E.A. (1987d). Recycled turn beginnings: A precise repair mechanism in conversation's turn-taking organization. In G. Button \& J.R.E. Lee (Eds.) Talk and social organization (pp. 70-85). Clevedon, England: Multilingual Matters.

Schegloff, E.A. (1991). Conversation analysis and socially shared cognition. In L.B. Resnick, J.M. Levine, \& S.D. Teasley (Eds.), Perspectives on socially shared cognition (pp. 150-171). Washington DC: American Psychological Association.

Silverman, D. (1987). Communication and medical practice. London: Sage.

Suchman, L. (1987). Plans and situated actions: The problem of human-machine interaction. Cambridge: Cambridge University Press.

Telephone Helplines Association (1999). Guidelines for good practice $\left(3^{\text {rd }}\right.$ Ed). London; Telephone Helplines Association.

van Dijk, T.A. (1997). The study of discourse. In van Dijk, T.A. (Ed.). Discourse as structure and process (pp. 1-34). London; Sage.

Whalen, M.R. \& Zimmerman, D.H. (1987). Sequential and institutional contexts in calls for help. Social Psychology Quarterly, 50 (2), 172-185. 
Whalen, M.R. \& Zimmerman, D.H. (1990). Describing trouble: Practical epistemology in citizen calls to the police. Language in Society, 19, 465-92.

Whalen, J., Zimmerman, D.H. \& Whalen, M.R. (1988). When words fail: A single case analysis. Social Problems, 35 (4), 335-362.

Wiggins, S. \& Potter, J. (in press). Attitudes and evaluative practices: Category vs. item and subjective vs. objective constructions in everyday food assessments, British Journal of Social Psychology.

Wooffitt, R. (1992). Telling tales of the unexpected: The organization of factual discourse. London: Harvester/Wheatsheaf.

${ }^{1}$ For a rebuttal of Jeff Coulter's recent critique of discursive psychology, see Potter \& Edwards (in press).

2 The current corpus is over 200 calls. We continue to collect with a particular interest in some rather less common types of calls (for example calls by children and calls that combine reports of violence with racist abuse.

${ }^{3}$ Baker et al., (2001) suggest that in software helpline calls the RFC is typically organized in a narrative form. They suggest that this provides the caller a way of presenting as already having investigated the problem or at least noted its repetition before calling.

4 This intuition can be fleshed out with some counting of calls. In a subset of 17 calls (these calls are often very long, only a proportion had a full searchable transcript at the time of writing) concerned/s appears an average of 7 times per call while worried/s appears 3 times a call. Is this a lot? We can do a rough comparison with other materials. In the Holt corpus of 67 everyday phone calls there are just two occurrences of 'concerned', both in the context of the idiom 'as far as I was concerned'. Worried appears 16 times, but still at an average of less that 0.3 per call. What about other institutional materials? In the Edwards corpus of 
relationship counselling sessions concerned/s appears just 4 times in 5 hour long sessions ( 3 as part of 'as far as I was concerned' and one 'all we was concerned about was going down the pub'). There is prima facie evidence, then, that the prevalence of concerned and concerns in this material is notable. It should not be taken too seriously, however, as it is focused on the appearance of lexical items rather than the organization of activities.

5 In 21 of the calls the caller starts with a construction that has them 'being concerned' or 'having concerns' (or 'worries/ied'). In a further 9 calls even though the caller has not used this construction the CPO uses such a construction attributively (see Table 1 for summary). Broadly, we can see that $60 \%$ of calls start with concern constructions, and of these about two thirds are initiated by the caller and a third by the CPO. Note also the way callers use 'concerned' and 'worried' constructions the majority of the time, yet CPOs use 'concern/s' and ‘worries' exclusively.

Table 1: Distribution of concern constructions

\begin{tabular}{l|cc} 
& Caller first & CPO First \\
\hline Concerned & 15 & 0 \\
Concern/s & 4 & 8 \\
Worried & 1 & 0 \\
Worries & 1 & 1 \\
Total & 21 & 9
\end{tabular}

${ }^{6}$ Childline is a UK helpline that specialises in counselling children about abuse.

7 Note that there is some difference between the way the topic of concern is formulated. Such differences are beyond the scope of this paper.

8 NSPCC calls unfold in a complex and varied manner, subject to a wide range of contingencies. In this call, for example, it is not until 7 minutes into the call that the CPO broaches the likely upshot. 


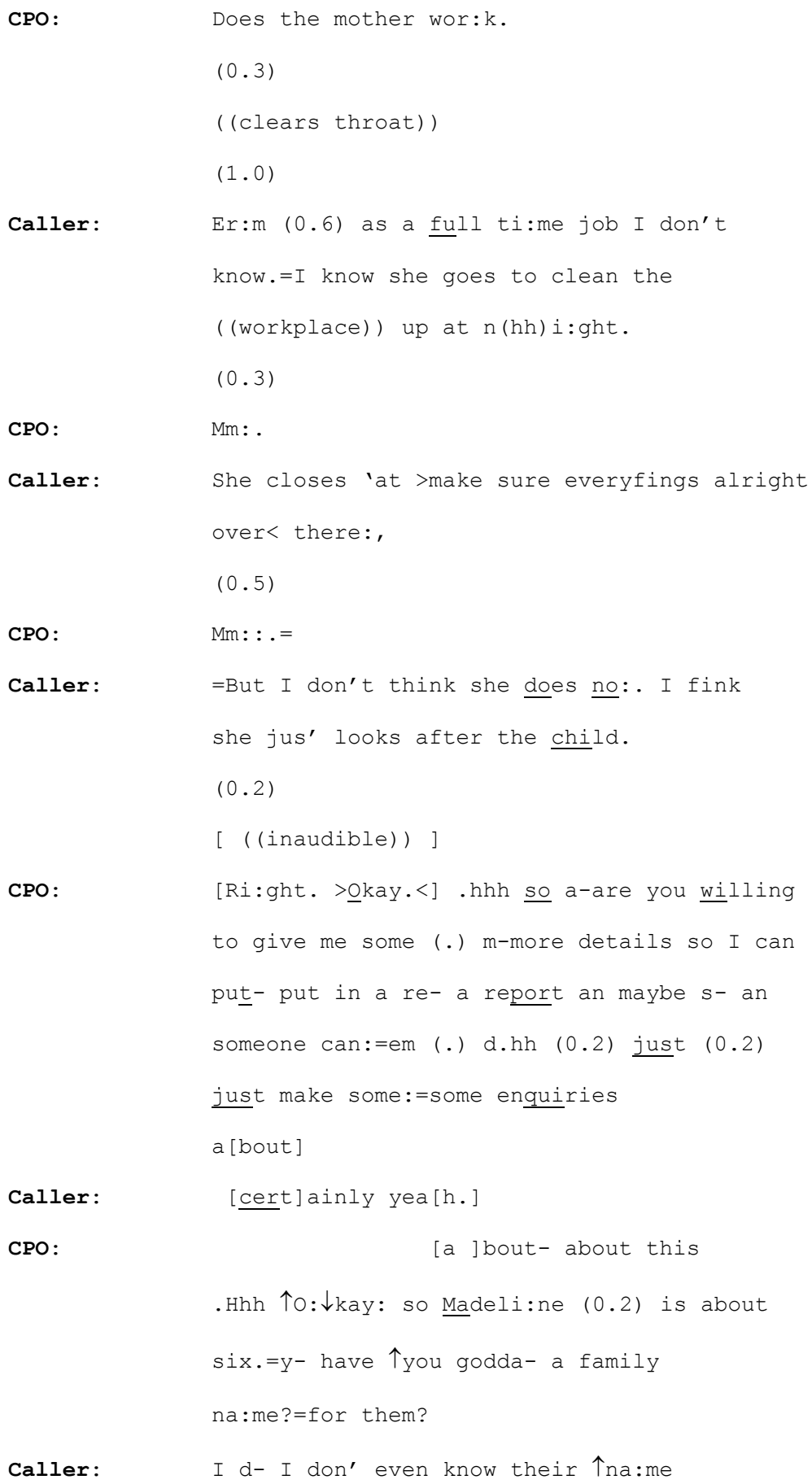

The call continues with further questioning (about the ethnicity of the family, about 'comings and goings', about other things that might 'raise concern', and so on). Details of the callers name and address are taken and he is given further assurances that a referral will be made. The complete call lasts 15 minutes, which makes it just under average length for the NSPCC abuse calls in our corpus. 
9 The significance of this emphasis on developing his own version may be related to the more direct stake in the outcome that a father might show compared with a neighbour.

10 Note that it may not be the concern construction per se that does the projecting. Rather, it is likely to be the concern construction in this slot in the call. That is, the concern construction's projecting work is partly a consequence of what it does not do, namely provide a full reason for call.

11 There is a complexity here that is worth noting as it may occur regularly in these calls where the one party (the CPO) is very familiar with their trajectory and the other, the caller, is often going to be making such a call for the first time. The question 'how old is your son' may be a question designed to collect information while not interfering with the unfolding of an abuse report (indeed, it may show attention and interest); however, the caller may take a question such as this to be the start of the CPO guiding the call. We can speculate that there may be something of a dilemma here for the $\mathrm{CPO}$ with respect to their questioning of the caller. In this case the father's displayed concern for his son, or the potential lack of importance of a complaint about school discipline for the helpline, might motivate a concern with keeping control over the delivery of the story.

12 This extract also illustrates another feature of the use of 'concerned'. Concerned can be upgraded or downgraded, or modified in other ways. Only 7 out of 30 are modified in this way, so we will be cautious about over interpreting this small set of calls, but it is at least suggestive that the 4 upgraded instances of concerned ('very'/"particularly') appear in calls where the call is a second call or where the caller is reporting someone else being concerned. It may be that upgrading the concern provides accountability for the second call or for the more indirect reporting of another's concern. On the other hand, downgraded examples ('bit'/'little'/'small') leave the trajectory of the call most open. More work would be needed to establish this claim more solidly.

13 See note 3 for more of this sequence.

14 It is interesting to note here that although the callers start of the reason for call sequence is not concern constructed, the CPO repackages it in this way following the ethics exchange. It is notable that the CPO does not say that she will consider what advice to offer, but they will jointly decide what course of action to take. The advice opening to the RFC is treated as the preliminary to a report of some kind. 
15 This is comparable to relationship counsellor's constructing conflicts and disputes as problems that may have an appropriate counselling solution (Edwards \& Potter, 2001).

16 The following is a numerical breakdown. It should be treated cautiously as the categories are not always clear cut. Nevertheless, it highlights a general pattern.

Table 2: Classes of calls where concern constructions are less common.

\begin{tabular}{l|ccc} 
& $\begin{array}{c}\text { Institutional Identities } \\
\text { Concern construction }\end{array}$ & $\begin{array}{c}\text { Speaking on behalf of } \\
\text { another }\end{array}$ & $\begin{array}{c}\text { Requesting } \\
\text { advice }\end{array}$ \\
\hline Non-concerns & 0 & 1 & 3 \\
& 4 & 5 & 5
\end{tabular}

17 This is a complicated issue of course. Although Mothers may normatively be expected to know about their daughters this is just the kind of normative expectation that the CPOs might be cautious of accepting to readily.

18 This call continues as follows:

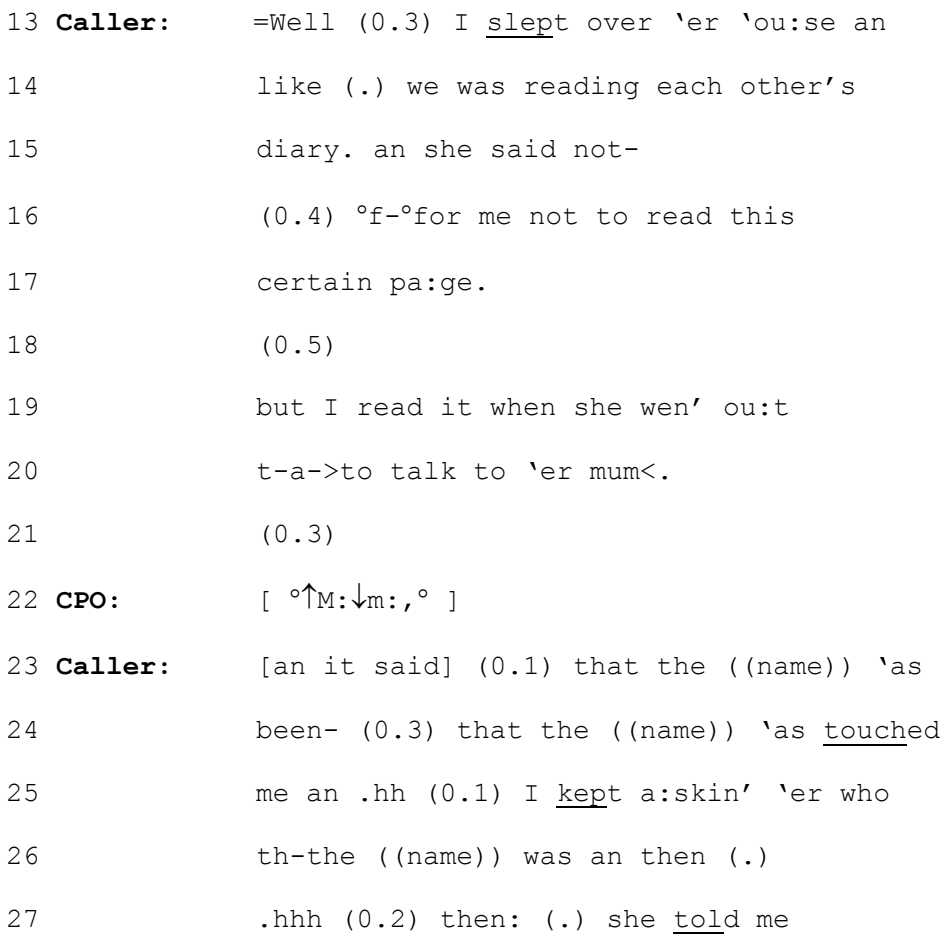




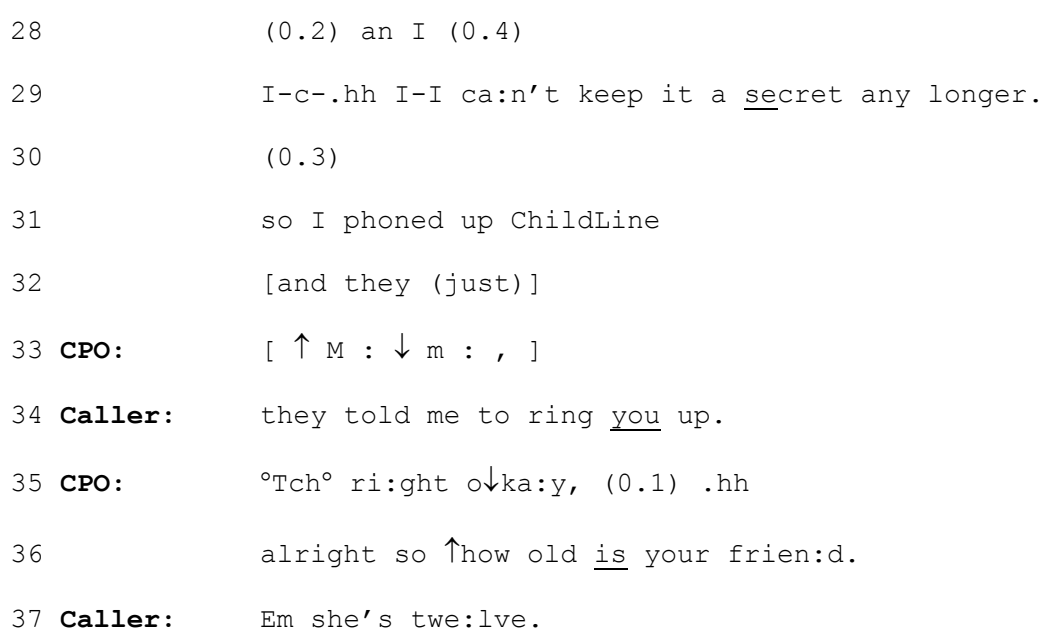

19 It might be thought that callers are registering their actual uncertainty when they open calls in this way, and their uncertainty is one basis for calling a helpline rather than one of the more directly intervening agencies. However, this interpretation does not fit the overall organization of the calls. Although callers pervasively open in a tentative manner this is probably best seen as an orientation to the institutional tasks of unpacking evidence rather than a characterisation of an enduring position on the abuse. Indeed, it is likely (and there is evidence of this within the calls) that callers are reluctant to call the NSPCC and so weigh up the issues carefully, often talking them over with others. It is not uncommon for them to express strong views about the factuality of the abuse at later stages in the calls, particularly in the face of questioning that may suggest doubts on the part of the CPO.

20 It is possible to wonder which came first - do CPO's use concern because callers routinely do or vice versa. This would be something of a chicken and egg approach. We would rather emphasise that this construction is effective for both caller and CPO and therefore that as competent language users they might both be expected to use it, or something like it, unprompted. The same issue goes for the NSPCC's publicity materials. The small print on posters sometimes uses concern constructions, e.g. from a current poster: 'a qualified child protection officer will talk with you about your concerns and decide with you if action is necessary'. 